
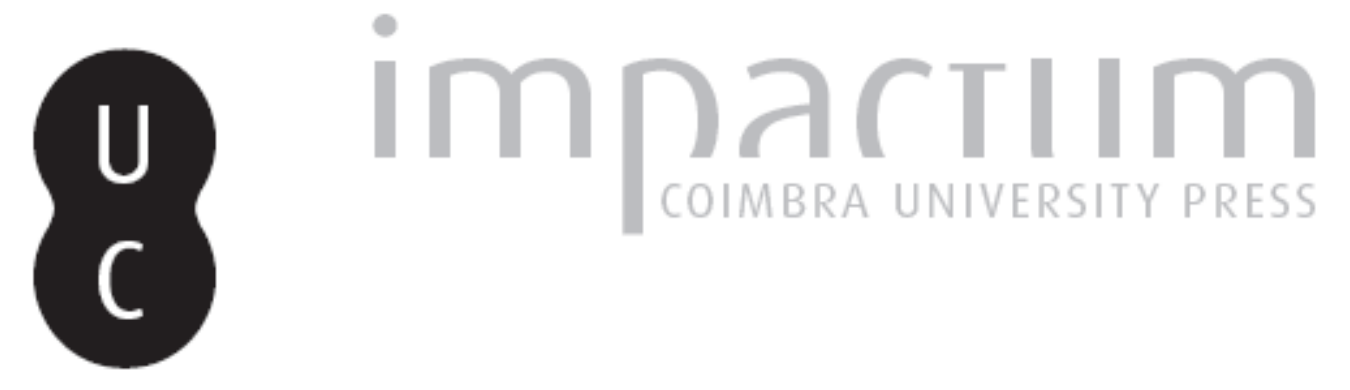

Fragmentos de pergaminho na Torre do Tombo: um inventário possível (1315-1683)

Autor(es): $\quad$ Pinto, Pedro

Publicado por: Centro de História da Sociedade e da Cultura

URL persistente:

URI:http://hdl.handle.net/10316.2/39360

DOI:

DOI:http://dx.doi.org/10.14195/1645-2259_14_2

Accessed : $\quad$ 26-Apr-2023 01:57:03

A navegação consulta e descarregamento dos títulos inseridos nas Bibliotecas Digitais UC Digitalis, UC Pombalina e UC Impactum, pressupõem a aceitação plena e sem reservas dos Termos e Condições de Uso destas Bibliotecas Digitais, disponíveis em https://digitalis.uc.pt/pt-pt/termos.

Conforme exposto nos referidos Termos e Condições de Uso, o descarregamento de títulos de acesso restrito requer uma licença válida de autorização devendo o utilizador aceder ao(s) documento(s) a partir de um endereço de IP da instituição detentora da supramencionada licença.

Ao utilizador é apenas permitido o descarregamento para uso pessoal, pelo que o emprego do(s) título(s) descarregado(s) para outro fim, designadamente comercial, carece de autorização do respetivo autor ou editor da obra.

Na medida em que todas as obras da UC Digitalis se encontram protegidas pelo Código do Direito de Autor e Direitos Conexos e demais legislação aplicável, toda a cópia, parcial ou total, deste documento, nos casos em que é legalmente admitida, deverá conter ou fazer-se acompanhar por este aviso. 


\section{4 \\ 2014}

\section{evista de História da Sociedade e da Cultura}

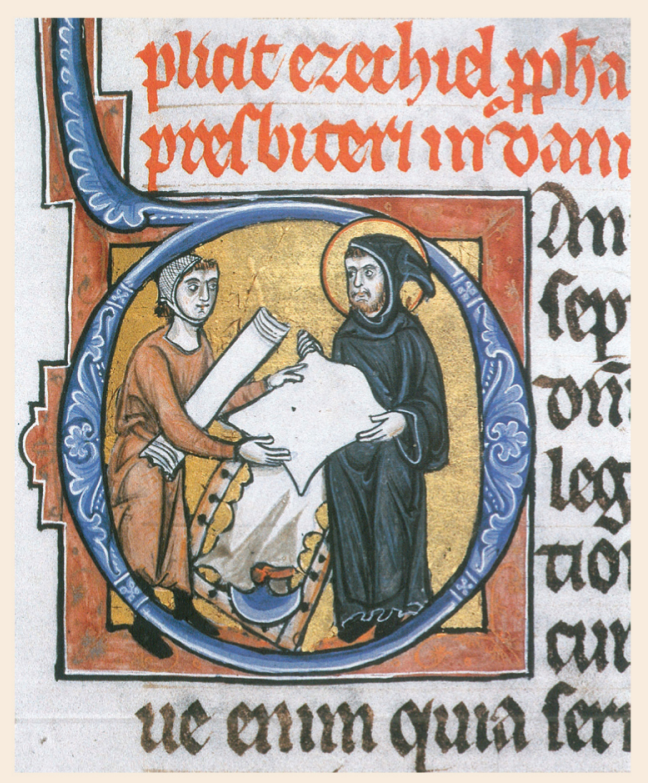

Centro de História da Sociedade e da Cultura Universidade de Coimbra 


\title{
Fragmentos de pergaminho na Torre do Tombo: um inventário possível (1315-1683)
}

\author{
Pedro Pinto \\ Centro de Estudos Históricos da Universidade Nova de Lisboa \\ Centro de História d'Aquém e d'Além-Mar, Faculdade de Ciências Sociais e Humanas, \\ Universidade Nova de Lisboa, Universidade dos Açores \\ pedroacpinto@yahoo.com.br \\ Texto recebido em/Text submitted on: 21.06 .2014 \\ Texto aprovado em/Text approved on: 14.01.2015
}

\section{Resumo/Abstract:}

Os fragmentos de pergaminho medievais e modernos foram desprezados e ignorados por séculos e só começam a ser revalorizados a partir do século XX, fruto de iniciativas individuais de investigadores. Este trabalho descreve o que tem sido feito em Portugal neste campo e apresenta um inventário detalhado de 108 fragmentos portugueses encontrados na Torre do Tombo.

Medieval and modern parchment fragments have been neglected and ignored for centuries on and only were appreciated in the 20th century, due to individual projects carried out by researchers. This work aims at describing what has been done in Portugal in this field and presents a detailed inventory of 108 Portuguese fragments found in the Portuguese National Archive (Torre do Tombo).

Palavras chave/Keywords:

Fragmentos; Inventários; Torre do Tombo.

Fragments; Inventories; Torre do Tombo. 
Fragmentos de pergaminhos usados como folhas de guarda ou de encadernação improvisada em códices e documentos avulsos abundam em todos os arquivos europeus e nos mais diversos fundos e colecções, bem como em bibliotecas que possuem incunábulos ou livros impressos até ao século XVIII. Em Portugal, existem encadernações com essas características em fundos provenientes do Tribunal do Santo Ofício, Misericórdias, Câmaras Municipais, Conventos, Colegiadas, Notários, Paróquias, Juízos de Órfãos, entre outros, deixando antever que a reconversão dos pergaminhos e códices medievais fosse um acto corriqueiro, em particular nos séculos XVI a XVIII ${ }^{1}$, quando a palavra impressa começou a triunfar sobre a palavra manuscrita. Outros factores contribuíram para este processo de mutilação, fragmentação e destruição, como fossem: a cópia de documentos de difícil leitura ou cujo suporte ficasse fragilizado, tornando desprezível o original; as mudanças nas tendências literárias e correntes teológicas; e a actualização dos códices litúrgicos face à reforma pós-tridentina e a dos códices de natureza jurídica face à nova produção legislativa.

Esses fragmentos foram então usados para encadernar documentos ou códices, evitando-se o custo de um pergaminho novo ou de uma encadernação mais robusta e, em alguns casos, libertando espaço nas bibliotecas monásticas e cartórios municipais, sendo até vendidos a peso, por exemplo, a livreiros. ${ }^{2}$

1 Cronologicamente haverá excepções, a mais notável sendo a do distrito de Leiria para o período pós-Invasões Francesas, momento de forte disrupção dos circuitos de aquisição de bens e matérias-primas. Cerca de $20 \%$ dos fragmentos existentes no Arquivo Distrital encadernam livros de 1800 a 1819, mas bem adentro do século XIX ainda se encontra quase uma centena de fragmentos, sobretudo no concelho de Alcobaça (VINAGRE, Ana Bela da Silva - Manuscritos de Capas de Livros Paroquiais e Notariais do Arquivo Distrital de Leiria, do Séc. XII a XIX (Inventário Preliminar). In II Colóquio sobre História de Leiria e da sua Região: Actas, II. Leiria: Câmara Municipal de Leiria, 1995, p. 13-54).

2 COSTA, Avelino de Jesus da - Fragmentos Preciosos de Códices Medievais. Bracara Augusta. I, 13 (1949) 425-426; PELLEGRIN, Elizabeth - Fragments et Membra Disiecta. Codicologica. 3 (1980) 72-74; BANDEIRA, Ana Maria Leitão - Pergaminho e papel em Portugal: tradição e conservação. Lisboa: Celpa BAD, 1995, p. 15, 24; PICKWOAD, Nicholas - The Use of Fragments of Medieval Manuscripts in the Construction and Covering of Bindings on Printed Books. In BROWNRIGG, Linda L. \& SMITH, Margaret M. (eds.) - Interpreting and Collecting Fragments of Medieval Books. Los Altos Hills, California: Anderson Lovelace Pub., 2000, p. 1-20; ALTURO I PERUCHO, Jesús - Les études sur les fragments de manuscrits en Espagne: Bilan et considérations diverses. Revista de História da Sociedade e da Cultura. 12 (2012) 83-85; SEIXAS, Maria Margarida Faria Ribeiro da Cunha de Castro - A encadernação manuelina a consagração de uma arte: estudo das suas 
Há claros indícios da importação de França de pergaminhos para esses fins, o que explica as centenas de pergaminhos em francês que se encontram nos arquivos nacionais. ${ }^{3}$ As espécies em alemão, castelhano, grego, holandês ${ }^{4}$ e inglês são raras.

A par das catástrofes naturais, das guerras ${ }^{5}$ e da supressão dos conventos e ordens religiosas (processo que se arrastou pelos séculos XIX e XX) $)^{6}$, a destruição deliberada de documentação ao longo dos séculos, e que

características e evolução, em bibliotecas públicas portuguesas. Salamanca: Universidad de Salamanca, 2013, p. 711-712. Em 1521, respançavam-se (i.e., raspavam-se) pergaminhos para reutilização, dada a escassez e custo de tal material nobre (BRAGA, Paulo Drumond Fornecimentos de pergaminhos, papel e tinta a diversos serviços da administração (Fevereiro de 1521). Revista Portuguesa de História. XXIX (1994) 213-228).

3 Em 1554, uma carta de quitação indica a aquisição pela Chancelaria da Corte e Casa da Suplicação de 189 dúzias de "porgaminhos por Respamçar pera stprever" e 49 dúzias de "porgaminhos Respamçados" (IANTT, Chancelaria de D. João III, Privilégios, Liv. 4, f. 201), e em 1575 e 1576 os mesmos organismos tinham adquirido 116 dúzias de "porgaminhos de framdes Respançados" e 54 dúzias de "porgamjnhos de castella" (IANTT, Chancelaria de D. Sebastião, Privilégios, Liv. 11, f. 186v. ${ }^{\circ}$ ). COSTA, Avelino Jesus da Fragmentos..., cit., p. 425. Cf., para a identificação de capas francesas, AZEVEDO, Pedro de - Novos fragmentos de uma canção de gesta francesa do séc. XIV. Anais das Bibliotecas e Arquivos de Portugal, II Série, I (1920) 308; GROER, Léon de, e VIANA, Abel - Capas de pergaminho em livros antigos do Arquivo Camarário de Beja. Arquivo de Beja. 6 (1949) 86-96; CRUZ, Maria Leonor García da - Colecção de incunábulos e impressos raros dos séculos XV-XVI na Biblioteca Digital da Faculdade de Letras da Universidade de Lisboa. Comentário ao manuscrito que serviu de capa a "Sanctiones Apostolicae Extravagantes... Lisboa, António Gonçalves, 1570 - Res 261. Clio: Revista do Centro de História da Universidade de Lisboa. II Série, 18-19 (2008) 535-543; CORREIA, Isabel Calvário e MIRANDA, José Carlos Ribeiro - Os fragmentos A19 da Biblioteca Geral da Universidade de Coimbra e a tradição textual do Lancelot. In Seminário Medieval, 2009-2011. Porto: Seminário Medieval de Literatura Pensamento e Sociedade, 2011, p. 13-48.

4 ABEL, Firmino - Pergaminho voa até Leiden-Holanda. Santa Casa: Revista da Santa Casa da Misericórdia de Vila do Conde. 8 (1998) 25-26.

5 COELHO, Maria Helena da Cruz - No rasto da guerra - o antes e o depois. In VI Jornadas Luso-Espanholas de Estudos Medievais: A Guerra e a Sociedade na Idade Média, I. Lisboa: Sociedade Portuguesa de Estudos Medievais, 2009, p. 287-306. Para além dos prejuízos causados pelas intervenções militares inimigas em tempos de escassez de matérias-primas, há que contar também com a voluntária reciclagem de papel para servir a indústria de armamento militar, como ocorreu no Reino Unido durante a II Guerra Mundial, e que implicou a destruição de documentação até mesmo do séc. XVIII (THORSHEIM, Peter - Salvage and Destruction: The Recycling of Books and Manuscripts in Great Britain during the Second World War. Contemporary European History. 22, 3 (2013) 431-452).

${ }^{6}$ ERDMANN, Carl - A secularização dos arquivos da Igreja em Portugal. Anais das Bibliotecas e Arquivos de Portugal. II Série, VIII, 29-32 (1927) 48-57; COSTA, Avelino Jesus da - Fragmentos..., cit., p. 426; RAMOS, Luís A. de Oliveira - A Extinção das 
continuou até aos nossos dias, é uma das principais responsáveis pelas graves lacunas documentais de que muitos investigadores se queixam. ${ }^{7}$ Além disso, muitos fundos documentais foram vítimas de incúria. Uns apodreceram e outros desapareceram, devido a roubo ou incêndio. ${ }^{8}$

Quando os fragmentos são reutilizados para capas, a destruição, felizmente, nem sempre é completa, embora a exposição aos elementos e à acção humana por meio do manuseamento mais ou menos frequente do livro, tenha provocado a sua natural erosão. A violência sobre o texto da face exterior adensou-se frequentemente com a aposição, a tinta, sobre a "nova" capa, da identificação temática e cronológica do livro, tornando ainda mais difícil ao actual investigador recuperar totalmente a informação original. A frágil condição de muitos dos fragmentos sobrevivos teve ainda de suportar a praxis arquivística do Arquivo Nacional da Torre do Tombo e de muitos dos Arquivos Distritais nos anos que se seguiram à incorporação de fundos notariais, paroquiais e religiosos. Ao organizarem tais fundos, os funcionários ou técnicos inscreveram sobre as capas, usando lápis, tinta e autocolantes, as diferentes cotas que foram sendo dadas aos livros e que são, de forma trágica e singular, um testemunho eloquente da evolução das

Ordens Religiosas: Consequências culturais. Bibliotheca Portucalensis. II Série, 7 (1992) 7-26; BARATA, Paulo J. S. - Roubos, extravios e descaminhos nas livrarias conventuais portuguesas após a extinção das ordens religiosas: um quadro impressivo. Lusitania Sacra, 2. ${ }^{a}$ Série, 16 (2004) 319-343.

7 COSTA, Avelino Jesus da - Fragmentos..., cit., p. 425.

8 Cf. AZEVEDO, Pedro de - Os archivos eclesiasticos da Guarda. O Archeologo Português. 9 (1904), p. 296-300; CALDAS, José - História de um fogo morto: subsídios para uma história nacional: 1258-1848: Viana do Castelo. Porto: Livraria Chardron, 1904, p. 435-437; AZEVEDO, Pedro de - Os cartórios da Inspecção de Finanças de Lisboa destruídos pelo recente incêndio. Boletim da Segunda Classe da Academia das Ciências de Lisboa. XIII (1919) 674-675; GUERRA, L. de Figueiredo da - Os arquivos do Alto-Minho. Anais das Bibliotecas e Arquivos de Portugal. II Série, II, 6 (1921) 157-158, 235-238, 330-332; ARQUIVO DE BEJA - O incêndio da Câmara Municipal de Beja: Quanto se perdeu e o que resta do arquivo antigo. Arquivo de Beja. 4 (1947) 364-394; BRÁSIO, António O Tombo do Infante D. Pedro em Penela. Arquivo Coimbrão. XXI-XXII (1967) 497-501; SOUSA, Fernando de - Relatório dos Arquivos a Norte do Douro. Revista de História Económica e Social. 3 (1979) 109-119; SERRÃO, Joaquim Veríssimo - Impõe-se a fundação do Arquivo Histórico de Santarém. In Páginas da História de Santarém. Lisboa: Academia Portuguesa da História, I, 2008, p. 247-252; PINTO, Pedro - Fragmentos de registos paroquiais quinhentistas de Castelo de Vide (e algumas considerações sobre arquivos de Portalegre). Raizes e Memórias. 29 (2012) 293-316. 
práticas arquivísticas do País e do desprezo a que estas peças históricas, algumas verdadeiros tesouros, foram votadas até à actualidade. ${ }^{9}$

Na realidade, alguns dos fragmentos que sobreviveram até à actualidade enquanto capas de livros são o único testemunho material da chamada "literatura perdida", abrangendo os mais diversos ramos do saber medieval. Esta é formada por obras de que se tem notícia indirecta mas cujos testemunhos desapareceram quase por completo. Uma noção o mais aproximada possível da dimensão do que se perdeu ajuda a contextualizar e valorizar a literatura extante. ${ }^{10}$

Esta realidade literária e histórica tem interessado investigadores em outros países da Europa, como na Alemanha, Espanha, França, Hungria, Itália e Reino Unido. Refira-se, a título de exemplo, os cerca de 22.500 fragmentos existentes no Arquivo Nacional da Suécia, cuja catalogação se iniciou na década de 1930 e foi concluída seis décadas mais tarde, ou os 9.319

9 Veja-se, como epítome desta praxis, ADL, Cartório Notarial de Torres Vedras, Liv. 70. Sobre a face exterior do pergaminho encontramos a inscrição do notário indicando a cronologia dos actos contidos no livro. Da responsabilidade do arquivo, encontramos uma inscrição a tinta e outra a lápis azul contendo basicamente a mesma informação, esta última abarcando quase metade da mancha de texto, culminando com a aposição de um autocolante que cobre uma parte das últimas três linhas do texto medieval. Na face interior, há ainda uma nova inscrição da cota, a lápis. O texto medieval, em português, pertence à obra de João Cassiano, Estabelecimentos dos Mosteiros, traduzida provavelmente no final do primeiro quartel do séc. XV (RICO, Maria João Toscano - A projecção da obra de João Cassiano na Península Ibérica: elenco de testemunhos e edição de textos inéditos. Euphrosyne. XL (2012) 123-148).

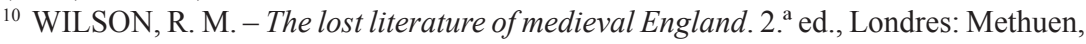
1970; DEYERMOND, A. Lost Literature in Medieval Portuguese. In MICHAEL, Ian e CARDWELL, Richard Andrew (eds.) - Medieval and Renaissance Studies in Honour of Robert Brian Tate. Oxford: Dolphin Book, 1986, p. 1-12; DEYERMOND, A. - La Literatura perdida de la Edad Media castellana. Catálogo y estudio. I: Épicas y romances. Salamanca: Ediciones Universidade de Salamanca, 1995, p. 17-28; DEYERMOND, A. The Lost Literature of Medieval Portugal: Further Observations. In EARLE, T. F. \& GRIFFIN, Nigel - Portuguese, Brazilian, and African Studies. Studies presented to Clive Willis on his retirement. Warminster: Aris \& Phillips, 1995, p. 39-49; NASCIMENTO, Aires A. - Novos fragmentos de textos portugueses medievais descobertos na Torre do Tombo: horizontes de uma cultura integrada. Península: Revista de Estudos Ibéricos. 2 (2005) 7-24; MOREIRA, Filipe Alves - Um novo fragmento da Crónica Portuguesa de Espanha e Portugal de 1341-1342 e suas relações com a historiografia alfonsina. In Seminário Medieval, 2009-2011. Porto: Seminário Medieval de Literatura Pensamento e Sociedade, 2011, p. 289-322. 
fragmentos existentes na Finlândia, já catalogados e acessíveis em http:// fragmenta.kansalliskirjasto.fi/, num projecto iniciado na década de $1840 .{ }^{11}$

A investigação em arquivos e bibliotecas nacionais e estrangeiras ${ }^{12}$ visando a identificação de fragmentos portugueses de natureza literária iniciou-se há muitas décadas atrás. Após um período inicial de publicação avulsa ou identificação de fragmentos de forma casuística, que teve lugar no final do século XIX e primeiros anos do século $\mathrm{XX}^{13}$, deveu-se a Avelino Jesus da Costa o primeiro trabalho de fôlego sobre o tema. De 1944 a 1952,

${ }^{11}$ KER, N. R. - Fragments of medieval manuscripts used as pastedowns in Oxford bindings, with a survey of Oxford binding c. 1515-1620. Oxford: A.T. Broome, 1954; MEZEY, László - Fragmenta Latina codicum in Bibliotheca Universitatis Budapestinensis. Budapeste: Akadémiai Kiadó, 1983; POWITZ, Gerhardt (ed.) - Mittelalterliche Handschriftenfragmente der Stadt- und Universitätsbibliothek Frankfurt am Main, Frankfurt am Main: Klostermann, 1994; PERANI, Mauro - Un decennio di ricerca dei frammenti di manoscritti ebraici in Italia. Annali di Storia dell'Esegesi. 12, 1 (1995) 111-127; BROWNRIGG, Linda L. e SMITH, Margaret M. (eds.) - Interpreting and Collecting Fragments of Medieval Books. Los Altos Hills, California: Anderson Lovelace Pub, 2000; LE SAGE DE LA HAYE, Yves - Répertoire numérique de la série I: feuillets et fragments de livres manuscrits, avec et sans notation musicale, IXe-XVIe siècles. Tours: Archives départementales d'Indre-et-Loire, 2001; TAITTO, Ilkka - Catalogue of medieval manuscript fragments in the Helsinki university library. Fragmenta membranea IV:1-2. Antiphonaria. Helsinki: Helsingin yliopiston kirjasto, 2001; ALTURO I PERUCHO, Jesús - Les études..., cit., p. 79-112; BRUNIUS, Jan - From Manuscripts to Wrappers: Medieval Book Fragments in the Swedish National Archives. Stockholm: Riksarkivet, 2013.

${ }^{12}$ Em Espanha também se encontraram fragmentos portugueses de valor literário (MARTINS, Mário - Os fragmentos da «Legenda Áurea» em medievo-português. Itinerarium. VIII, 35 (1962) 47-51; LORENZO, Ramón - Un fragmento dun manuscrito medieval do Livro da Montaria de D. Joao I de Portugal. Verba. 27 (2000) 9-32).

${ }^{13}$ BRAGA, Teófilo - Questões de literatura e arte portuguesa. Lisboa: A. J. P. Lopes, 1881, p. 128-139; AZEVEDO, Pedro de - Dois fragmentos de uma vida de S. Nicolau do sec. XIV em português. In Bausteine zur romanischen Philologie, Festgabe für Adolfo Mussafia. Halle: Max Niemeyer, 1905, p. 581-586; SOLALINDE, Antonio G. - Fragmentos de una traducción portuguesa del Libro de Buen Amor de Juan Ruiz. Revista de Filología Española. I, 2 (1914) 162-172; BRANCO, Luís de Freitas - Música e instrumentos. In A questão iberica. Lisboa: Tipografia do Anuário Comercial, 1916, p. 124-126; AZEVEDO, Pedro de - Fragmento de um tratado de teologia do sec. XV em português. Revista Lusitana. XIX (1916) 36-39; VASCONCELOS, António de - Fragmentos preciosos de dois códices paleogràfico-visigóticos. Biblos. IV (1928) 553-569; IDEM - Notas litúrgico-bracarenses. In Acta do Congresso Litúrgico Nacional Romano-Bracarense. Braga: Edição da Empresa «Acção Católica», 1928, p. 204-216, 228-237; PÉREZ DE URBEL, Justo - La liturgia de los fragmentos bracarenses. Opus Dei. III (1928-1929), 319-327; BRANCO, Luís de Freitas Elementos de Sciências Musicais. Leipzig: Ed. autor, Vol. II, 1931, p. 27-29; PRADO, Germán - La antigua melopea bracarense. Opus Dei. IV (1929-1930) 186-200; VASCONCELOS, António de - Fragmento precioso dum códice visigótico. Biblos. V (1929) 245-273. 
sob patrocínio do Instituto para a Alta Cultura, percorreu o País e elaborou um conjunto de relatórios contendo a descrição de cerca de 1.500 fragmentos encontrados em arquivos e bibliotecas. O seu alvo eram as obras de natureza literária, normativa e litúrgica, em latim e em português. Os dados obtidos foram frutuosamente aproveitados nas décadas de 1950 e 1960 por Mário Martins e por Luís F. Lindley Cintra, abrindo novas perspectivas sobre o horizonte literário medieval português. ${ }^{14}$

Seguiram-se algumas iniciativas episódicas de identificação de várias tipologias de fragmentos ${ }^{15}$, incluindo textos em hebraico ${ }^{16}$, desenhos numismáticos ${ }^{17}$ e mapas. ${ }^{18}$

Um rastreio mais cabal dos fragmentos apenas se tornou possível, mais recentemente, e desde 1988, graças à equipa da BITAGAP (Bibliografia de Textos Antigos Galegos e Portugueses), da Universidade da Califórnia, que tem vindo a identificar os textos portugueses anteriores a $1501 \mathrm{de}$ natureza literária e histórica, excluindo os notariais. Todos os testemunhos manuscritos desses textos são pesquisáveis na Base de Dados PhiloBiblon (http://bancroft.berkeley.edu/philobiblon/), que inclui os testemunhos materiais conservados também em fragmentos pergamináceos. Um conjunto impressionante de resultados desse labor, no que tange aos fragmentos da Torre do Tombo, foi publicado em 2002, mas a equipa tem continuado a

${ }^{14}$ COSTA, Avelino Jesus da - Fragmentos..., cit., p. 421-434; IDEM - Fragmentos Preciosos de Códices Medievais. Bracara Augusta. II, 1 (1950) 44-62. Existe uma cópia mimeografada dos relatórios na Sala de Reservados da Biblioteca Nacional. Cf. MARTINS, Mário - Fragmentos medievais portugueses. Brotéria. L, 4 (1950) 403-414; CINTRA, Luís Filipe Lindley - Sobre uma tradução portuguesa da General Estoria de Afonso X. Boletim de Filologia. XII (1951) 184-191; MARTINS, Mário - Fragmento de um tratado de teologia do séc. XV em português. Brotéria. LXXV (1962) 416-423.

${ }^{15}$ CORBIN, Solange - Essai sur la Musique Religieuse Portugaise au Moyen Âge (1100-1385). Paris: Les Belles-Lettres, 1952; PORTUGAL, Fernando - A Chancelaria de D. Manuel. Ethnos. Revista do Instituto Português de Arqueologia, História e Etnografia. 6 (1969) 261-270; CEPEDA, Isabel Vilares - Um fragmento inédito das «Vidas e Paixões dos Apóstolos». Boletim de Filologia. XXIV (1975) 295-304.

${ }^{16}$ TAVARES, António Augusto - Manuscrito hebraico e aramaico em Lisboa. Didaskalia. VIII, 1 (1978) 187-194; TAVARES, António Augusto e COHEN, Dov - Novos manuscritos hebraicos. Didaskalia. XXV, 1-2 (1995) 189-194.

${ }^{17}$ FARIA, Miguel Figueira de - Francisco de Holanda desenhador de moedas: um novo testemunho documental. Leituras: Revista da Biblioteca Nacional. 2, 1997, p. 181-188.

${ }^{18}$ MARQUES, Alfredo Pinheiro - Alguns fragmentos de mapas encontrados em Viana do Castelo... Revista da Universidade de Coimbra. XXXV (1989) 309-322. 
publicar os resultados da investigação subsequente realizada nesse e em outros arquivos. ${ }^{19}$

O projecto mais recente nesta área é o FRAGMED, coordenado pelo Prof. Saul Gomes, e que se propôs, em meados da década passada, fazer um levantamento sistemático dos fragmentos e da sua tipologia textual a nível dos arquivos e bibliotecas nacionais. Dois bolseiros trabalharam em Arquivo Distritais, Municipais e de Misericórdias, mas não na Torre do Tombo, identificando as cotas e tipologia textual e, frequentemente, obtendo reprodução fotográfica dos fragmentos. Aguarda-se o carregamento final da base de dados na Internet (http://fragmed.net/). ${ }^{20}$

Algumas instituições têm destacado esses fragmentos dos livros notariais e paroquiais e criado, desta forma, uma colecção de pergaminhos ${ }^{21}$, ao passo que outras fazem um levantamento das suas cotas, disponibilizando-as aos investigadores. ${ }^{22}$

${ }^{19}$ ASKINS, Arthur L.-F. et alii - Fragmentos de textos medievais portugueses da Torre do Tombo. Lisboa: Instituto dos Arquivos Nacionais-Torre do Tombo, 2002; IDEM et aliiUm novo fragmento da General Estoria de Afonso X em português medieval. Santa Barbara Portuguese Studies. 6 (2002a) 134-156; DIAS, Aida Fernanda - A matéria de Bretanha em Portugal: relevância de um fragmento pergamináceo. Revista Portuguesa de Filologia. XXV, 1-2 (2003) 145-222; cf. ainda SHARRER, Harvey L. - Fragmentos de sete cantigas d'amor de D. Dinis, musicadas: uma descoberta. In NASCIMENTO, Aires A. e RIBEIRO, Cristina Almeida - Literatura Medieval: Actas do IV Congresso da Associação Hispânica de Literatura Medieval, I. Lisboa: Edições Cosmos, 1991, p. 13-29; FERREIRA, Manuel Pedro - Relatório preliminar sobre o conteúdo musical do Fragmento Sharrer. In Actas do IV Congresso da Associação Hispânica de Literatura Medieval, I. Lisboa: Edições Cosmos, 1991, p. 35-42; GUERRA, António J. R. - Contributos para a Análise Material e Paleográfica do Fragmento Sharrer. In Actas do IV Congresso da Associação Hispânica de Literatura Medieval, I. Lisboa: Edições Cosmos, 1991, p. 31-34.

${ }^{20}$ GOMES, Saul António - O Projecto FRAGMED - Corpus Portugaliae Fragmentorum. Biblos. II Série, IV (2006) 355-358; IDEM e REBELO, António Manuel Ribeiro Do Fragmento ao Saber: o Projecto FRAGMED - Corpus Portugaliae Fragmentorum. Forma Breve: Revista de Literatura. 4 (2006) 65-80. O Arquivo Distrital de Évora possui para consulta uma cópia impressa do relatório relativo aos seus fragmentos.

${ }^{21}$ Como a Biblioteca Pública de Évora, o Arquivo Municipal de Elvas e o Arquivo do Cabido da Sé de Portalegre (MARTINS, Anacleto Pires da Silva - O cabido da Sé de Portalegre: Achegas para a sua história, Portalegre, 1997).

${ }^{22}$ Como os Arquivos Distritais de Portalegre, Setúbal, Leiria e Viseu (cf. HENRIQUES, Maria das Dores Almeida - Fragmentos que serviram, ou servem, de encadernação de livros no Arquivo Distrital de Viseu. Viseu: Arquivo Distrital de Viseu, 1997; CANCELA, Rui Jorge Lopes - Subsídios codicológicos para o estudo dos fragmentos do Arquivo Distrital de Viseu: Os fragmentos do Cabido da Sé. Beira Alta. LXIII, 1-2 (2004) 173-234; IDEM - Subsídios 
Paralelamente a estes projectos sistemáticos, outros investigadores têm-se dedicado à identificação, publicação e estudo de fragmentos, em particular desde a década de 1980. Um campo de particular incidência tem sido o dos fragmentos litúrgico-musicais ${ }^{23}$, de cujos estudos Manuel Pedro Ferreira tem sido o grande dinamizador nos últimos anos. De particular destaque em outro campo, o dos fragmentos latinos, tem sido Aires A. Nascimento ${ }^{24}$.

codicológicos para o estudo dos fragmentos do Arquivo Distrital de Viseu: Os fragmentos do Cabido da Sé. Beira Alta. LXIII, 3-4 (2004a) 447-506).

${ }^{23}$ JORDAN, W. D. - Um fragmento de música antiga no Arquivo Municipal de Ponte de Lima - Observações sobre o estilo Aquitano. Arquivo de Ponte de Lima. IV (1983) 203-236; IDEM - O Estilo Musical na Liturgia de Portugal no século XIII, interpretado através do Fragmento VIII, Arquivo Municipal de Lisboa. Bracara Augusta. XLI, 104-105 (1988) 3-40; BARBOSA, J. Alves - A música na liturgia bracarense nos séculos XII e XIII. O reportório musical da missa nos fragmentos de códices do Arquivo Distrital de Braga. Modus: Revista do Instituto Gregoriano de Lisboa. 3 (1989-1992) 81-271; FERREIRA, Manuel Pedro - Relatório preliminar..., cit., p. 35-42; QUEIRÓS, Abílio - Fragmentos de Pergaminho Litúrgico-Musicais: Inventário Geral. 1. ${ }^{\mathrm{a}}$ parte. Boletim do Arquivo da Universidade de Coimbra. XIII-XIV (1993) 325-348; BRAGANÇA, Joaquim O. - Fragmento precioso de um Missal de Braga do Século XII. Theologica. XXVIII, 2 (1993) 375-390; FERREIRA, Manuel Pedro - Three Fragments from Lamego. Revista de Musicología. XVI (1993) 457-476; QUEIRÓS, Abílio - Inventário dos Fragmentos Litúrgico-Musicais existentes no A.U.C. (2. ${ }^{a}$ parte). Boletim do Arquivo da Universidade de Coimbra. XV-XVI (1995) 517-547; CARVALHO, Joaquim Félix de - Fragmentos litúrgicos de Braga. Didaskalia. XL, 2 (2010) 93-111; FERREIRA, Manuel Pedro - Um fragmento de Alcobaça, o canto dos pregadores e os seus livros de coro na Biblioteca Nacional. In IV Congreso Internacional sobre el Císter en Portugal y Galicia: Actas, II. Zamora: Ediciones Monte Casino, 2010, p. 721-741; IDEM - Cluny no Cabo do Mundo: um costume, três fragmentos. In FERREIRA, Manuel Pedro - Aspectos da Música Medieval no Ocidente Peninsular, II. Lisboa: IN-CM, 2010, p. 83-118; IDEM - Harmonias do Céu e da Terra: a música nos manuscritos de Guimarães, séculos XII-XVII: The music in the manuscripts of Guimarães, 12th-17th centuries. Lisboa; Publischer, 2012; IDEM - Dating a Fragment: A Cistercian Litany and its Historical Context. In SCAPPATICCI, Leandra (ed.) - 'Quod ore cantas corde credas': Studi in onore di Giacomo Baroffio Dahnk. Roma: Libreria Editrice Vaticana, 2013, p. 293-313; NELSON, Bernadette - Fragments of Fifteenth-Century Northern Propers in Portugal. In BURN, David J. \& GASCH, Stefan (eds.) - Heinrich Isaac and polyphony for the proper of the mass in the Late Middle Ages and Renaissance. Turnhout: Brepols, 2011, p. 61-80.

${ }^{24}$ CORTEZ, Fernando Russell - Uma possível folha de cronicão medieval. In Congresso Histórico de Guimarães e sua Colegiada: Actas, V. Guimarães, 1981, p. 17-20; GARCIA Y GARCIA, António - Fragmentos de manuscritos del Decreto y de las Decretales de Gregorio IX en Portugal. Revista da Universidade de Coimbra. XXXV (1989) 357-360; NASCIMENTO, Aires A. - Um fragmento de sermão do século XIII em honra de Santo António: a águia, o anjo e o livro. In Congresso Internacional Pensamento e Testemunho: 8. ${ }^{\circ}$ Centenário do Nascimento de Santo António: actas, Braga: Universidade Católica Portuguesa, 1996, p. 917-936; IDEM - Um fragmento de Differentiae uerborum em letra carolina. Euphrosyne. XXXII (2004) 265-282; IDEM - Festus ex recensione Pauli: fragmentos 
Naturalmente, os fragmentos portugueses, de vária natureza, têm continuado a ser trabalhados. ${ }^{25}$ Neste particular, as obras de Pedro Comestor e de Afonso X, como as Partidas ou a General Estoria, têm tido vários cultores. ${ }^{26}$

$\mathrm{O}$ trabalho que aqui apresentamos focaliza-se nos textos portugueses que pudemos identificar na Torre do Tombo. ${ }^{27}$ A primeira parte deste inventário incide nos textos de proveniência notarial, cartas régias ou de oficiais da Coroa que hoje servem de capas de documentos ou códices e como folhas

de letra carolina em arquivos portugueses. Euphrosyne. XXXIII (2005) 429-446; IDEM Fragmento Olisiponense das Falsas Decretais. In Estudos em Homenagem ao Prof. Doutor Martim de Albuquerque, I. Coimbra: Coimbra Editora, 2010, p. 37-54; IDEM-S. Vicente de Lisboa: legendas, milagres e culto litúrgico (testemunhos latinomedievais). Lisboa: Centro de Estudos Clássicos, 2011; DOMINGUES, José - Um fragmento (português) da Summa Hostiensis. e-SLegal history review. 14 (2012) 1-14.

${ }^{25}$ PENSADO TOMÉ, José L. - Fragmento de un "Livro de Tristán" galaico-português. Santiago de Compostela: CSIC, 1962; CEPEDA, Isabel Vilares - Os "Quarenta Mártires de Sebaste". Um testemunho manuscrito do século XV em português. Theologica. XXVIII (1993) 507-514; FERREIRA, Manuel Pedro - Cantus coronatus: 7 cantigas d'El-Rei Dom Dinis by King Dinis of Portugal. Kassel: Reichenberger, 2005.

${ }^{26}$ FERREIRA, José de Azevedo - Dois fragmentos da «Terceira Partida» de Afonso X. Cahiers de linguistique hispanique médiévale. 5 (1980) 101-141; IDEM - Subsídios para uma edição da Terceira Partida de Afonso X. Boletim de Filologia. XXIX (1984) 111-118; IDEM - Dois fragmentos da Segunda Partida de Afonso X. Arquivos do Centro Cultural Português. XXIII (1987) 271-301; IDEM - A Primeira Partida de Afonso X: versões portuguesas. Revista da Faculdade de Letras, V. a Série, 13-14 (1990) 165-172; DIAS, Aida Fernanda - As "Partidas" de Afonso X: novos fragmentos em língua portuguesa. Revista Portuguesa de Filologia. XX (1992) 91-124; FERREIRA, José de Azevedo - Fragmentos das Partidas de Afonso X reencontrados em Braga. Cahiers de linguistique hispanique médiévale. 18-19 (1993) 367-402; IDEM - Um fragmento reencontrado da Terceira Partida de Afonso X. In PEREIRA, Cilene da Cunha e PEREIRA, Paulo Roberto (eds.)-Miscelânea de estudos lingüísticos, filológicos e literários: in memoriam Celso Cunha. Rio de Janeiro: Nova Fronteira, 1995, p. 573-596; DIAS, Aida Fernanda - As Partidas de Afonso X: novos fragmentos em língua portuguesa. Romance Philology. 54 (2000) 262-275; FERREIRA, José de Azevedo - Un nouveau fragment de la Terceira Partida d'Alphonso X. In Estudos de História da Língua Portuguesa: Obra dispersa. Braga: Centro de Estudos Humanísticos, 2001, p. 319-338; ASKINS, Arthur L-F., et alii - Um novo fragmento da General Estoria de Afonso X em português medieval. Biblos. II Série, IV (2006) 93-124; PINTO, Pedro Um novo fragmento português medieval da Terceira Partida de Afonso X. Boletim da Direcção-Geral de Arquivos. 8 (2009) 5; LEITE, Mariana - Os testemunhos da tradução portuguesa da Historia Scholastica de Pedro Comestor: consequências ideológicas da selecção de fontes. Cahiers d'Études Hispaniques Medievales. 33 (2010) 183-194; IDEM - A General Estoria de Afonso X em Portugal: as múltiplas formas de receção do texto alfonsino entre os séculos XIV e XVI. Porto: Faculdade de Letras da Universidade do Porto, 2012.

${ }^{27}$ Agradece-se a colaboração e disponibilidade dos Drs. Paulo Tremoceiro e Adelaide Proença, técnicos superiores da Torre do Tombo. 
de guarda de códices, ou inclusivamente já desintegrados dos códices e documentos, mas ainda mantendo a cota actual no Arquivo.

Não incluímos a descrição dos fragmentos, quase todos em papel que, ao longo do tempo, foram incorporados pelo Arquivo Nacional na colecção de Fragmentos. Esta colecção foi formada inicialmente a partir de documentos truncados, fragmentados ou danificados, e que não foram integrados, após o Terramoto de 1755, nas colecções do Corpo Cronológico, Cartas Missivas, Cartas dos Vice-Reis da Índia, Cartas dos Governadores de África e Núcleo Antigo. Constituída por 22 Caixas, num total de 69 maços, a colecção de Fragmentos contém também alguns fragmentos em pergaminho que foram removidos de livros notariais ou de fundos de instituições religiosas, sobretudo em latim. ${ }^{28}$ Como alguns destes fragmentos contêm textos literários ou normativos portugueses, apresentamos, em apêndice, uma lista actualizada dos fragmentos dessa natureza na Torre do Tombo, em pergaminho, quer estejam nos fundos originais quer tenham sido destacados para a colecção de Fragmentos.

Sendo normalmente ignorados pela maioria dos investigadores, estes documentos trazidos agora à luz do dia podem revelar dados hstóricos importantes. Em virtude da sua dispersão nos diversos fundos do Arquivo Nacional, apresentamos um resumo do seu conteúdo e uma listagem adicional de nomes próprios e localidades referidas em cada documento e que não constam do resumo.

Em virtude da sua natureza fragmentada, tendo sido amputados de secções por forma a servirem adequadamente uma nova função enquanto capa ou folha de guarda, a muitos dos textos falta a data, início ou fim do documento, obrigando a datar criticamente muitos deles e a apresentar resumos muito lacunares de muitos outros. Foi a partir dos elementos constantes na mancha de texto disponível que se conseguiram reunir os dados possíveis para identificar o século, década ou ano aproximado de produção, bem como a sua tipologia e produtor do documento original. Fruto destes condicionalismos, há inclusivamente muitos nomes truncados, dos quais apenas se pôde discernir o nome próprio ou o patronímico.

${ }^{28}$ LEAL, Maria José da Silva - Fundos de Arquivos. 1. Fragmentos. 2. Núcleo Antigo. Nova História. 1 (1984) 144-159. 
É provável que haja mais alguns fragmentos portugueses na Torre do Tombo que desconhecemos ou não pudemos ver, dada a dimensão dos acervos preservados naquela instituição ou o extremo mau estado de conservação de algumas espécies. ${ }^{29}$ No futuro, novas adições poderão ser feitas, fruto de novas pesquisas.

\section{Inventário de fragmentos portugueses de pergaminho na Torre do Tombo ${ }^{30}$}

\section{Mosteiro de São Domingos de Lisboa, Livro 77}

[13--, Lisboa]

Fragmento de registo de herdades que pagam foro e pensão anualmente ao Mosteiro de São Domingos de Lisboa.

Outros Antropónimos: [...] Martins; Afonso de Água [?]; Afonso Eanes Carragueiro; Afonso Peres; Almirante; Catarina Paris; Catarina Peres, mulher de Pero Esteves do Hospital; Clara Esteves, mulher de Pero de Unhão; Domingos Joanes, laudator; Estêvão Bretão; Estêvão Peres; Estêvão Peres Ravão; Gomes Lourenço de Car[...]; Isabel Martins, mulher de João Domingues; João Afonso; Frei João da Água Alva, frade de São Domingos; João Domingues; João Domingues Vergilhos; João Franco; João Loureiro, procurador na audiência; João Sanches; João Vicente; Lourenço Costas; Lourenço Maça; Lourenço Peres; Marão Vasques,

${ }^{29}$ Procurou-se ver todos os livros dos vários fundos e colecções existentes na Torre do Tombo. Contudo, a documentação de origem paroquial do ex-Arquivo Distrital de Lisboa foi microfilmada há muitos anos atrás e não incluía geralmente a captura das imagens das capas dos códices, sendo colocada uma folha branca ou preta a tapar a visualização das capas, o que não se compreende, até porque frequentemente essa folha criou uma faixa sombreada sobre a primeira ou última página contendo texto, tornando difícil a leitura de quem pretende consultar os registos paroquiais. $\mathrm{O}$ acesso aos originais é difícil, de acordo com a política arquivística em vigência de não permitir o acesso aos originais quando existe um outro suporte. Por fim, encontrámos casualmente alguns fragmentos a servirem de capas de documentos de um ou poucos mais fólios em maços de documentação conventual. Verificar as muitas dezenas de milhar de documentos dessa natureza existentes no Arquivo Nacional adiaria sine die a publicação do material até hoje recolhido.

${ }^{30}$ Inclui documentos em latim relacionados com Portugal. 
alfaiate; Maria Domingues, mulher de Vicente Esteves; Maria Esteves; Maria Geraldes, mulher de Domingos Joanes; Maria Lourenço, mulher de Lourenço Costas; Maria Ravoa; D. Maria Soares; Marinha das Portas; Martim Martins, carniceiro; Nicolau Peres; Pero Afonso Mealha; Pero Esteves do Hospital; Pero Esteves de Unhão; Pero Martins, sapateiro; Pero de Unhão; Teresa Lourenço, filha de Lourenço Peres; Teresa Peres, mulher de Martim Martins; Urraca Domingues; Vicente Eanes, sobrinho de Pero Esteves; Vicente Esteves, sapateiro.

Outros Topónimos: A-das-Lebres; Água Alva, termo de Sintra; Água Livre; Azóia; Belas; Carenque; Chelas; Coina; Colares; Conde Velho, herdade; Gondamar [?]; Madalena, freguesia; Pé de [...]; Pedras Negras; Penedo; Poço da Palha; Rio de Mouro; Rua dos Albardeiros; Rua Nova; Rua da Sapataria; Rua do Veado; Santa Bárbara; Santa Catarina de Ribamar; Santa Justa; Santa Maria da Escada; Santo Antão; São Marcos; São Nicolau; Sintra; Varatojo.

\section{Gavetas, XIX, Maço 14, Doc. 3 [1. ${ }^{\circ}$ documento $]^{31}$}

\section{$1315,[---]$, Setembro, 15}

Registo de resumo de carta régia de D. Dinis concedendo a D. Geraldo Domingues, bispo de Évora, a apresentação da igreja de São Miguel de Penela, que então tinha Vasco Martins da Ribeira, ordenando que o Bispo de Coimbra ou seus vigários lha confirmassem.

\section{Gavetas, XIX, Maço 14, Doc. 3 [2..$^{\circ}$ documento]}

\section{6, [---], Abril, 15}

Registo de resumo de carta régia de D. Dinis concedendo a D. Geraldo Domingues, bispo de Évora, a apresentação da igreja de São Miguel de Armamar, que então tinha Vasco Miguéis, cónego de Lamego, ordenando que o Bispo de Lamego ou seus vigários lha confirmassem.

${ }^{31}$ Em alguns casos, o mesmo fragmento contém mais do que um documento registado ou a capa é constituída por fragmentos provenientes de dois ou três pergaminhos originais diferentes. 


\section{Gavetas, XIX, Maço 14, Doc. 3 [3. ${ }^{\circ}$ documento]}

1318, [---], Dezembro, 20

Registo de resumo de carta régia de D. Dinis concedendo a D. Geraldo Domingues, bispo de Évora, a apresentação das igrejas de Santa Maria de Cedovim e Santiago de Marialva, no bispado de Lamego.

\section{Ordem de Cristo / Convento de Tomar, $307^{32}$}

\section{6, Lisboa, [---]}

Carta de Pedro de Labrunia, reitor da igreja de Colongis, diocese de Agen, núncio apostólico, com D. Raimundo, bispo de Coimbra, aos bispos de Lisboa, Coimbra, Porto, Viseu, Guarda, Lamego e Évora e a seus vigários, assim como aos abades, priores, reitores, arquipresbiteros, capelães e vigários, sobre a colecta dos resíduos das décimas sexenais e dos frutos dos beneficios em vacatura que até certo tempo viessem a vagar, e sobre outros direitos devidos ao Papa e à Câmara Apostólica. Contém outros documentos relacionados com o assunto.

Outros Antropónimos: Afonso Eanes, escudeiro; Afonso Gil; Afonso Rodrigues; Aparício Martins, clérigo da diocese de Coimbra, notário público; Mestre Domingos Martins, tabelião público de Lisboa; Estêvão Domingues, reitor da igreja de Sebal e raçoeiro de Coimbra; Estêvão Martins; Estêvão Vasques; Fernando Aires; Fernão Garcia, arcediago de Penela; Fernão Pais; Francisco Afonso, prior de Santa Justa de Coimbra; Garcia Martins; Gil Fernandes, mestre-escola; Gomes Martins dito Zote; D. Gonçalo, bispo de Lisboa; Mestre Gonçalo, doutor em Leis; Gonçalo Gonçalves; Guilherme de Buxa, notário da diocese de Rodes; Guilherme de Santo Jório, deão de Coimbra; Papa João XXII; João Eanes, advogado do Mestre; João Eanes, ouvidor do Mestre; João Fernandes; João Lourenço, Mestre da Ordem de Cristo; João Martins, alcaide de Lisboa; João Pais, cónego na igreja de

${ }^{32}$ Este sumário foi elaborado com base em notas cedidas por Mário Farelo, a quem muito agradecemos a leitura do fragmento em latim. 
Coimbra; João Peres; Lopo Martins; Lourenço Fernandes Albravis; Lourenço Peres; Martim Bulhão, chanceler do dito Mestre; Martim Esteves; Martim Lourenço; Martim Martins, cónego de Palença; Martim Peres; Martim Rodrigues; Martim de Vinho; Pedro Esteves; Pedro Fernandes; Pedro Gonçalves; Pedro dito Lemomnier, clérigo da diocese de Constância, notário público; Pedro Lopes, reitor de Podentes (Penela); Pedro Martins; Raimundo de Serra, reitor de Marinh, diocese de Rodes; Rodrigo Eanes, escudeiro; Rodrigo Guilherme; Rodrigo Lourenço, cavaleiro; Rodrigo Martins; Soeiro Eanes; Vasco dito Forque; Vasco Martins; Vicente Peres dito Bulhão.

Outros Topónimos: Avinhão; Braga; Burgos; Cartagena; Compostela; Constância; Léon; Marinh; Oviedo; Palença; Penela; Podentes; Rodes; Santa Maria do Açougue (diocese de Évora); Sevilha; Santiago (termo de Trancoso); Sebal; Soure; Toledo; Trancoso.

\section{Colegiada de Santa Maria da Oliveira de Guimarães, Livro 1}

[post. 1352, Abril, 8]

Inventário dos bens de Teresa Domingues, contendo a descrição de roupas, móveis, alfaias, etc.

Outros Antropónimos: Afonso Martins; Domingos Peres, testamenteiro; Gonçalo Eanes, ouvidor; João Fernandes, pregoeiro; João Gonçalves das Eiras; Salvador Fagundes.

\section{Ordem de Santiago / Convento de Palmela, 228}

[1352, Lisboa, Agosto, 30]

Capitulos gerais das Cortes de Lisboa de 1352. ${ }^{33}$

${ }^{33}$ Estes Capítulos Gerais foram publicados, embora a partir de outra fonte, em MARQUES, A. H. de Oliveira (ed.) et alii-Cortes Portuguesas: Reinado de D. Afonso IV (1325-1357). Lisboa: Instituto Nacional de Investigação Científica / Centro de Estudos Históricos da Universidade Nova de Lisboa, 1982. 


\section{Colegiada de Santa Maria da Alcáçova de Santarém, Maço 22, ${ }^{\circ}{ }^{\circ} 2$}

[post. 1362, Santarém, Março, 28]

Feito de João André contra o chantre e cónegos da igreja de Santa Maria da Alcáçova de Santarém.

Outros Antropónimos: [...] Afonso; Afonso Martins, capelão do rei; Domingos Eanes, tabelião em Santarém; Gil Afonso, cónego da igreja de Santa Maria da Alcáçova de Santarém; Gonçalo Chainho; Gonçalo Peres, ouvidor; Luís Domingues; João de Parada; Martim Gomes, tabelião; Pedro Serras, escrivão da audiência; Pero Lourenço, chantre; D. Teobaldo, bispo de Lisboa; Vasco Lourenço, procurador na audiência do bispo.

Outros Topónimos: Lisboa; Santa Maria de Marvila.

\section{Colegiada de São Miguel de Torres Vedras, Livro 5 [1. ${ }^{\circ}$ documento]}

1375, Lisboa [?], Abril, 26

Documento relacionado com uma quartanaria na Sé de Lisboa.

Outros Antropónimos: Álvaro Martins, porteiro do cabido; Fernão Geraldes, tabelião; Gonçalo Eanes; Gonçalo Martins; João Eanes; João Martins, abade; Paio Martins.

\section{Colegiada de São Miguel de Torres Vedras, Livro 5 [2. ${ }^{\circ}$ documento]}

1378, Torres Vedras, Julho, 7

Carta de aforamento que faz a Colegiada de São Miguel de Torres Vedras a Vicente Mateus, dito Bispo, almocreve, morador em Torres Vedras, de um lugar na dita vila denominado de Cacavelos por três libras e meia por ano. Contém o traslado de uma carta de Guilherme Cartonel, vigário por D. Agapito de Caluna, Bispo de Lisboa e prior da igreja de Santiago de Beja, bacharel em degredos, a Lourenço Afonso, raçoeiro da igreja de São Miguel de Torres Vedras, a pedido de Gonçalo Martins, prior da igreja de São Miguel, concedendo licença para se fazerem emprazamentos e aforamentos (1377, Lisboa, Janeiro, 18). 
Outros Antropónimos: Fernando Esteves; Gonçalo Eanes, filho de João Domingues; Gonçalo Martins, prior da igreja de São Miguel; Gonçalo da Ovelheira, prioste; Mestre João, físico; João Domingues; João Esteves, tabelião; Martim Martins, sobrinho de Mestre João, físico; Pedro Afonso Sintrão.

\section{Ordem de Avis / Convento de São Bento, Livro 32}

[1392]

Fragmento de livro de pagamentos da Coroa (?). ${ }^{34}$

Outros Antropónimos: Catarina Eanes, manceba do Infante D. João; Domingos Eanes; Gil Esteves, mestre da carpintaria real; Infante D. João; João Afonso, juiz.

Outros Topónimos: Londres; Porto.

\section{Gavetas, XIII, Maço 1, Doc. 25}

[14-- $],[\ldots]$

Posturas sobre arrais e marinheiros ordenada por Fernão de Queirós [?].

\section{Cabido da Sé de Lamego, Livro 169}

[14--], [Lamego]

Testamento de $[\ldots]$.

Outros Antropónimos: [...] Estêvão; Fernão Martins; Maria Álvares; Maria Rodrigues.

${ }^{34}$ Temos já identificados mais alguns fragmentos pertencentes ao mesmo códice original que foi esquartejado para servir de folhas de guarda para as encadernações dos forais manuelinos. Assim que tivermos conseguido verificar todas as folhas de guarda dos forais ainda remanescentes em bibliotecas e arquivos, publicaremos os textos na íntegra. Sobre o desmantelamento de códices no âmbito desta reforma dos forais, cf. NASCIMENTO, Aires A. - Festus ex..., cit., p. 429-446. 
Outros Topónimos: Carvalhosa; Mosteiro de São Jorge de [...]; Portela de Alvelos; Porto Cavalar (Lamego); Santa Maria de Almacave; Santa Maria de Alvelos; São Francisco de Viseu.

\section{Mosteiro de Lorvão, Gaveta 1, Maço 9, Doc. 4, $\left[2 .^{\circ}\right.$ documento $]$}

[14--], Coimbra (Capela do Espírito Santo da Igreja de Santa Justa de Coimbra), Março, [---]

Instrumento de emprazamento que faz a Colegiada de Santa Justa de Coimbra a João Porto, sapateiro, de um cortinhal perto da igreja onde jaziam as mós junto ao adro, após renúncia de João Eanes, besteiro, por trinta soldos da moeda antiga e uma galinha por ano.

Outros Antropónimos: Estêvão Gonçalves, escrivão do corregedor; Garcia Gonçalves, raçoeiro; Gonçalo Eanes, raçoeiro; Gonçalo Gonçalves, prior; João Álvares, raçoeiro; João da Arruda, raçoeiro; João Gonçalves, tabelião geral em Entre-Douro e Mondego; Luís Peres; Martim Álvares, barbeiro; Pero Dias, criado de Vasco Afonso, raçoeiro; Pero Gonçalves, prioste da igreja; Rodrigo Eanes, porteiro do corregedor; Vasco Afonso, raçoeiro.

15. Cartório Notarial de Torres Vedras, Liv. de Notas, "Cartório", Liv. 51

[14--], [---], Junho, [--]

Aforamento de chão que faz D. Isabel, viúva do Porteiro-Mor, em nome de suas filhas órfãs, a Afonso Fernandes.

Outros Antropónimos: Antão Martins, cavaleiro da Casa Real e juiz dos órfãos; Francisco de Pina, tabelião; D. Isabel; Jorge Fernandes, ferrador; Pero Fernandes, escrivão dos órfãos; Pero Luís, alfaiate; Silvestre Gonçalves, escudeiro de D. Isabel; Vasco Vieira, escudeiro e tabelião em Lisboa.

Outros Topónimos: Lisboa. 


\section{Ordem de Santiago / Convento de Palmela, 62}

\section{[1401?]}

Registo de uma auditoria feita a um tesoureiro da Casa da Moeda, alistando a quantidade e a qualidade das ligas de pratas fundidas para criar o peelado. ${ }^{35}$

Outros Antropónimos: Domingos Eanes; Domingos Peres.

\section{Núcleo Antigo, 303}

[post. 1417, Coimbra, Junho, 14]

Carta de sentença definitiva de Afonso Lopes, cónego na Sé de Coimbra e vigário-geral no espiritual e temporal da dita sé vacante, sobre uma demanda entre Gil Eanes sobrinho de Vasco Gil, ferreiro, morador na Lousã, autor e demandador por Gonçalo Eanes, bacharel em leis, seu procurador, contra Maria Martins, filha de Martim Domingues, morador na Lousã, ré, defendedor por André Eanes, escolar em direito, seu procurador. Gil Eanes tinha casado com Maria Martins, sendo transcritos os seus votos de casamento, mas alegava que ela não era boa esposa.

Outros Antropónimos: Afonso Domingues, escudeiro; Diogo Peres, filho de Pedro Afonso; Gonçalo Eanes do Rego, procurador.

\section{Cartório Notarial de Torres Vedras, Liv. de Notas, "Cartório", Liv. 36 [3. ${ }^{\circ}$ Documento]}

[post. 1439, Torres Vedras, Junho]

Registo de dois instrumentos, o primeiro uma carta de venda que faz Gonçalo Martins a João da Rousida e Leonor Esteves, sua mulher, de uma courela de herdade, por 700 reais brancos; o segundo, um instrumento de

${ }^{35}$ Publicado em HENRIQUES, António Castro - Um Fragmento da Casa dos Contos e o seu Contributo para a História Monetária. Fragmenta Historica, 1 (2013) 109-120. 
doação que faziam João da Rousida e Leonor Esteves, sua mulher, moradores em Torres Vedras, a Cristóvão Eanes, clérigo, seu filho, da herdade acima referida.

Outros Antropónimos: Afonso Eanes; Afonso Guterres, tabelião; Catarina Eanes, filha do Galhardo Velho; Diogo Álvares; Estêvão de Sá; Fernão de Elvas; Gil Vasques, tabelião; Gomes Eanes, escrivão das sisas; Jorge Esteves; Martim de [...]; Samuel Franco.

Outros Topónimos: Paço; Serra de Pedrulhos; Varatojo.

\section{Mosteiro de Santos-o-Novo, Caderno 4}

1442, Lisboa, Janeiro, 22

Carta régia de D. Afonso V sobre uma sentença envolvendo João Henriques, tabelião dos mouros da mouraria, e Inês Peres, sua mulher, e Lopo [...] e Catarina Rodrigues, sua mulher, sobre um desaguisado envolvendo a compra de lenha.

Outros Antropónimos: Gonçalo Eanes, escrivão; João Rodrigues, vassalo e ouvidor; Rui Taveira, vassalo e ouvidor.

\section{Juízo dos Órfãos de Vale de Cambra, Livro $6^{36}$}

[1444?]

Fragmento de regimento de almotaçaria.

\section{Mosteiro de Arouca, Gaveta 6, Maço 7, N. ${ }^{0} 26$}

1447, Cancelo, Fevereiro, 21

Instrumento de emprazamento que faz Rodrigo de Carvalho e sua mulher Joana Domingues, moradores em Cancelo, a Brás Afonso e Maria Afonso, sua mulher, do Campo das Forcadas, que traziam emprazado do Mosteiro

\footnotetext{
${ }^{36}$ Ultimamos a publicação deste fragmento com Sandra M. Pinto.
} 
de Arouca, por 400 reais brancos. Contém outorga do mosteiro de 13.5.1447 na pessoa da abadessa D. Isabel de Ataíde.

Outros antropónimos: Afonso Eanes de Basto; Afonso Gonçalves, ovençal; Álvaro Eanes dos Currais; Gonçalo Martins, tabelião; João Afonso, adagueiro; João Afonso de Pinheiro; João Eanes, alfaiate; Pero Brandão, tabelião; Vasco Eanes, clérigo e criado da abadessa.

\section{Mosteiro de Lorvão, Gaveta 1, Maço 9, Doc. 4, $\left[1 .^{\circ}\right.$ documento]}

1448, Coimbra (claustro da Sé), Janeiro, 15

Instrumento do emprazamento que faz o Cabido da Sé de Coimbra a Luís Álvares, soqueiro, e Maria Afonso, sua mulher, após renúncia de Gonçalo Eanes de Lotão, clérigo raçoeiro (por meio de uma procuração apresentada por Fernão Repote, cónego), de uma vinha com suas oliveiras, por quinze libras da moeda antiga de D. Pedro I e D. Fernando e dois capões por ano.

Outros Antropónimos: Gil Esteves; Gonçalo Vasques, tabelião em Coimbra; João Eanes, alfaiate; João Eanes, barbeiro; Pedro de Ataíde, deão.

\section{Mosteiro de Santa Maria da Estrela de Boidobra, Maço 1, Doc. 30}

1456, Alcobaça, Fevereiro, 8

Carta de D. Álvaro, Bispo de Silves, a Frei Rodrigo Lourenço.

\section{Cabido da Sé de Lamego, Livro 77}

1461, Roma, Maio, 18

Bula em latim.

Outros Antropónimos: Papa Bonifácio VIII; Geraldo Domingos de Magalhães; Gonçalo Rodrigues; João André; João Gobernari, prior; João Gonçalves David, presbítero; D. Luís, Bispo.

Outros Topónimos: Lamego; Roma; São Salvador da Várzea de Arouca; Mosteiro de São Vicente de Fora. 
25. Cartório Notarial de Torres Vedras, Liv. de Notas, "Cartório", Liv. 17

1461, Amial, Setembro, 30

Doação de uma herdade que fazem André Afonso e Beatriz Eanes, sua mulher, à Confraria de Nossa Senhora Santa Maria do Ameal, seguida de instrumento de posse da herdade pela dita confraria na pessoa do seu mordomo, o pintor João Álvares.

Outros Antropónimos: Aires Lourenço, fidalgo; Álvaro Gonçalves, tabelião; Diogo Álvares, escudeiro; João Eanes; João Gonçalves; Lopo Álvares, escudeiro.

Outros Topónimos: Torres Vedras; Turcifal.

\section{Núcleo Antigo, 563}

1465, Lisboa (freguesia de Santa Justa), Fevereiro, 1

Carta de venda que faz Branca Lopes, viúva e mulher que fora de Duarte Inglês, de uma quinta que tinha em Palma, no termo de Lisboa, que fora de João [...], tesoureiro da Moeda, a Tristão Inglês, cavaleiro da casa do rei, e seu almoxarife das taracenas, em paga de 3.000 reais brancos que the devia, com consentimento de Pero Gomes, escudeiro, filho de Gomes Martins, genro de Branca Lopes, e de Catarina Lopes, sua mulher, dos quais 3.000 reais brancos era fiador João Rodrigues, genro de Branca Lopes.

Outros Antropónimos: Álvaro de Gorizo; Fernão Peres, almocreve; Fernão Rodrigues, tabelião; Rui da Vila.

\section{Núcleo Antigo, 542}

[1469-1501]

Carta régia confirmando uma decisão judicial envolvendo um quereloso chamado André [...] e que culminou no degredo do réu.

Outros Antropónimos: João Fernandes Godinho, bacharel em leis e vassalo; Pero [...], 


\section{Mosteiro de Arouca, Livro 225}

1470, Arouca, Julho, 6

Carta de emprazamento que faz o mosteiro de Arouca a Fernão Gonçalves e Catarina Gonçalves, de um casal em Ponte (Vouzela).

Outros Antropónimos: Afonso Rodrigues, escrivão dos prazos; Beatriz Pinta, subprioresa; Diogo de Amorim; Infante D. Fernando; Guiomar Ferreira, prioresa; João Alves, criado; D. Leonor Coutinho, abadessa.

29. Cartório Notarial de Torres Vedras, Liv. de Notas, "Cartório", Liv. 37 [1. ${ }^{\circ}$ Documento]

1470, Torres Vedras, Outubro, 14

Instrumento de venda que faz Afonso Vieira, escudeiro, morador em Torres Vedras, a Dinis Eanes, oleiro, e a Catarina Álvares, sua mulher, do pousio que tinha no Varatojo, perto da gafaria, por 150 reais brancos de moeda corrente.

Outros Antropónimos: [...] Gonçalves, tabelião; João de Ceuta; João Eanes, barbeiro; Lourenço Gonçalves Chambones; Pero de Elvas.

30. Cartório Notarial de Torres Vedras, Liv. de Notas, "Cartório", Liv. $36\left[1 .^{\circ}\right.$ Documento]

[1470?], [Torres Vedras?]

Instrumento de aforamento de herdades [?].

Outros Antropónimos: Daniel Gonçalves; Dinis Eanes, oleiro.

31. Cartório Notarial de Torres Vedras, Liv. de Notas, "Cartório", Liv. 36 [2. ${ }^{\circ}$ Documento]

[ant. 1480], [Lisboa?]

Carta régia de concessão de privilégio a [...] de não ser posto por besteiro ou servir nos encargos do concelho, a pedido de Rui Gomes de Alvarenga, conde palatino, da Casa da Suplicação. 
Outros Antropónimos: Álvaro Peres.

\section{Juízo dos Órfãos de Torres Novas, Livro 5}

1481, Alenquer, Dezembro, 6

Carta de sentença.

Outros Antropónimos: Álvaro Nunes, recebedor dos dinheiros e penas; Diogo Lopes, bacharel em leis; Fernando Álvares, escrivão; João da Palmeira, escrivão.

\section{Ordem de Santiago / Convento de Palmela, 172}

1485 [?], Viana do Alentejo, [---], 21

Instrumento de escambo que fazem Lourenço Vicente e Beatriz Vaz, sua mulher, de uns talhos de marinha por certas casas pertencentes a João Vicente e Iria Vaz, sua mulher.

Outros Antropónimos: Afonso Eanes, besteiro; Afonso Pires, filho de Pero Gomes; Álvaro Besteiro, serrador; Inês Gonçalves; João Rodrigues Mealheiro; Lourenço Afonso; Lourenço Vicente; Maria Gonçalves, mulher de João Rodrigues Mealheiro; Martim Afonso; Mem Fernandes, meirinho; Pero Gomes, cunhado de João Vicente; Vicente Esteves; Vicente Lopes.

\section{Convento de São Bento de Bragança, Livro 33}

14[86], Portel, Agosto, 2

Carta régia de perdão concedida a Estêvão Gomes, escudeiro, morador em Bragança, relacionada com um casamento que D. Fernando, duque de Bragança, fizera à força entre Genebra de Abreu, sua criada, e Gomes de Viseu. Contém registo do corregedor da comarca no verso.

Outros Antropónimos: Diogo Pinheiro, do Desembargo; D. Luís Pires, arcebispo de Braga, Bispo de Titopuly; Dr. Martim Pinheiro, do Desembargo; 
Pedro Eanes, corregedor em Trás-os-Montes; Pero Álvares; Rui Boto, Desembargador do Paço.

Outros Topónimos: Porto.

\title{
35. Juízo dos Órfãos de Castelo de Vide, Livro 4
}

1486, Castelo de Vide, Julho, [--]

Carta de venda que fazem [...] Mealha e Mécia Gonçalves de um chão em Castelo de Vide.

Outros Antropónimos: João Gonçalves; Vasco de Évora, escudeiro; Vasco Pires Colaço.

\section{Mosteiro de Lorvão, Gaveta 1, Maço 9, Doc. 4, $\left[3 .^{\circ}\right.$ documento]}

1490, Ventosa (Coimbra), Janeiro, 11

Instrumento de venda que fazem Álvaro Eanes, vendeiro, e sua mulher, Beatriz Álvares, moradores na Mealhada, a Gonçalo Gonçalves e Maria Vasques, sua mulher, moradores em Antes (hoje, Antas, Mealhada), de um cortinhal perto da Mealhada por 240 reais.

Outros Antropónimos: Afonso Eanes, carpinteiro; Afonso Gonçalves, gaiteiro; Fernão Gil, tandor; João Gonçalves, tabelião público;

\section{Ordem de Santiago / Convento de Palmela, 158}

\author{
1490, Évora, Abril, 7
}

Carta régia de emprazamento de um ferregial da Ordem de Santiago em Alcácer do Sal a Gonçalo Gomes, pintor.

Outros Antropónimos: Álvaro Lopes, secretário e cavaleiro da casa real; Antão Luís, escrivão; António Fernandes, escudeiro e almoxarife; Brás Álvares, escrivão da visitação.

Outros Topónimos: Setúbal. 


\section{Núcleo Antigo, 395}

1490, Fermedo, Novembro, 22

Carta de sentença de Rui Martins de Carvalho, cavaleiro da Casa Real, corregedor da Beira e Riba de Côa, endereçada aos juizes do concelho de Fermedo, sobre um feito envolvendo Afonso Lourenço, vereador e João Gonçalves, procurador do concelho, e demais moradores do concelho, como autores, de uma parte, e Pero Afonso, clérigo, cónego de Grijó, da outra parte, recebedor dos mogos e rendas do concelho pelo Bispo de Silves, que os havia por ser parente de Rui Pereira.

Outros Antropónimos: Rui Lopes, escrivão.

\section{Núcleo Antigo, 594}

1491, [...], Julho, 6

Carta de sentença de um feito envolvendo um furto tendo o réu sido condenado a degredo para Alcácer-Ceguer.

Outros Topónimos: Lisboa.

\section{Mosteiro de Arouca, Livro 7}

1494, Arouca, Julho, 28

Carta de emprazamento que o mosteiro de Arouca faz a Gonçalo Eanes e Isabel Gonçalves, sua mulher, de um casal denominado Outeiro em Santa Marinha de Fa[...], no julgado de Aguiar [de Sousa], termo do Porto, pagando 2.000 reais brancos por ano.

Outros Antropónimos: André Eanes, filho de João Eanes de Monção; Branca Correia, prioresa; D. Catarina Teixeira, abadessa; Estêvão de Figueiredo, procurador do mosteiro; Gonçalo Álvares, morador em Arouca; Gonçalo de Beça, escrivão do mosteiro; João [...]; João Eanes de Monção; Maria Pimentel, subprioresa. 


\section{Manuscritos da Livraria, 2293}

[post. 1495], Coimbra, Março, 16

Instrumento de publicação de carta denunciatória.

Outros Antropónimos: Afonso de Barros, cavaleiro da Casa Real; Álvaro Pires, capelão; Mestre Bartolomeu; Diogo Arrais, escudeiro e cidadão; Diogo Gonçalves, cavaleiro; Mestre Estêvão de Morais, bacharel e cidadão; Fernando Álvares, escudeiro e tabelião em Coimbra; Fernão Pais, cónego do mosteiro de Santa Cruz de Coimbra; Gonçalo Pais; Gonçalo Privado, escudeiro e cidadão; Jerónimo Afonso, cónego regrante do Mosteiro de São Vicente de Fora; João de Barros, cavaleiro da Casa Real; João Gonçalves; João Martins, escrivão; D. João de Noronha, prior do mosteiro de Santa Cruz de Coimbra; João Pessoa, o moço, cidadão; João Pires, ferrador, morador na dita cidade; João Rebelo, cidadão e juiz de Coimbra; D. Jorge de Almeida, bispo de Coimbra; Jorge Fernandes, escudeiro e tabelião em Coimbra; Leonel de Matos, cidadão; Mestre Luís, procurador; Martim Gonçalves, clérigo de missa e beneficiado na igreja de Santiago de Coimbra e notário apostólico; Miguel Ângelo, secretário; Nuno Cotrim, tabelião e notário público; Pero Afonso; Pero Fernandes, capelão do bispo e notário apostólico; Pero Lopes, cidadão, contador e feitor da Casa do bispo; Pero Lopes de Mariz.

Outros Topónimos: Arganil; Coimbra; Mosteiro de Santa Cruz de Coimbra; Mosteiro de São Vicente de Fora; Tentúgal; Tojal.

\section{Mosteiro de Santa Cruz de Coimbra, 2. ${ }^{\mathrm{a}}$ inc., Livro 85}

[post. 1495], Coimbra, Abril, 5

Instrumento de publicação de carta denunciatória e declaratória.

Outros Antropónimos: Afonso de Barros, cavaleiro da Casa Real; Diogo Gonçalves, cavaleiro; Fernão Pais, cónego do mosteiro de Santa Cruz de Coimbra; Fernão Rodrigues; Jerónimo Afonso, cónego regrante do Mosteiro de São Vicente de Fora; João de Barros, cavaleiros da Casa Real; 
João Vaz, prior de Tercouso, clérigo de missa; D. Jorge de Almeida, bispo de Coimbra; Jorge Fernandes, escudeiro e tabelião em Coimbra; Lopo Pinto; Martim Gonçalves, clérigo de missa e beneficiado na igreja de Santiago de Coimbra e notário apostólico; Mestre Luís, procurador; Miguel Ângelo, secretário; Nuno Cotrim, tabelião e notário público; Nuno Pita, clérigo de missa; Pero Borges, prior de São Fagundo; [...] Gonçalves da Madalena.

Outros Topónimos: Arganil; Leiria; Mosteiro de Santa Cruz de Coimbra; Igreja de Santa Justa de Coimbra; Mosteiro de São Fagundo; São Vicente de Fora; Tercouso; Tojal.

\section{Juízo dos Órfãos de Ferreira do Alentejo, Livro 2}

149[5-1499], Santarém, Novembro, 15

Carta de sentença régia sobre uma resistência que fez [...] a um Gonçalo de Amores, alcaide de Ferreira do Alentejo, por causa de umas ovelhas que lhe tirara.

Outros Antropónimos: Afonso Eanes; Bartolomeu Rodrigues; João de Braga, do desembargo régio e procurador dos feitos e promotor da justiça; João de Trancoso, porteiro da audiência.

\section{Núcleo Antigo, 199}

[1495-1521]

Carta régia de perdão a João do Avelar, morador em Torres Novas.

Outros Antropónimos: Afonso Gonçalves; Diogo Caldeira, meirinho perante o ouvidor do sobrinho; Gomes Eanes, escrivão das fianças; Simão Machado, clérigo.

\section{Juízo dos Órfãos de Torres Novas, Livro 1}

[1495-1521], Santarém, [...], 5

Carta de sentença régia sobre um feito envolvendo Fernão Eanes, moleiro, e João Freire, escrivão do almoxarifado de Torres Novas. 
Outros Antropónimos: João Fernandes; João Lourenço, escrivão; Lopo da Fonseca.

\section{Juízo dos Órfãos de Aljustrel, Livro 3}

$$
1497,[\ldots],[\ldots], 08
$$

Carta de sentença do Cardeal D. Jorge, arcebispo de Lisboa, envolvendo um feito relacionado com o pagamento do dízimo.

Outros Antropónimos: [D. Afonso de Portugal], Bispo de Évora; Fernando Álvares; D. Lopo da Cunha, fidalgo da Casa Real; Lopo Mendes, morador em Moura.

Outros Topónimos: Évora.

\section{Juízo dos Órfãos de Almodôvar, Livro 1}

[post. 1497, Maio, 29]

Carta de sentença régia a Valentim Gonçalves, escudeiro da Casa Real, e juiz de fora em Beja, sobre um feito em que eram autores [...] Rodrigues, escudeiro da Casa Real, e Catarina Rodrigues, sua mulher, contra Teresa Rodrigues, viúva, todos moradores em Beja, em virtude de uma querela sobre a posse da antiga mesquita e casas a ela foreiras em Beja.

Outros Antropónimos: Beatriz Carreira, mãe de Teresa Rodrigues; João de Andrade, escudeiro régio; João Martins, almoxarife do Duque de Bragança; João Martins Jacominho; João de Pedroso, tabelião de Beja; Rui de Carvalho, tabelião em Beja; Teresa Rodrigues.

Outros Topónimos: Rua da Selaria (Beja)

\section{Registos Paroquiais, Torres Vedras, São Pedro da Cadeira, Livro B-1}

$$
\text { [1498-1508?, Lisboa?] }
$$

Carta de sentença régia sobre um feito envolvendo João [...] e D. Álvaro de Ataíde, fidalgo da Casa Real, acerca de uma capela. 
Outros Antropónimos: Álvaro Eanes, bacharel e procurador das capelas, albergarias e hospitais de Lisboa; Fernão Martins, mestre-escola.

Outros Topónimos: Azambujal de Alparete (?); Igreja de São Jorge.

\section{Ordem de Cristo / Convento de Tomar, 304}

1499, Torres Novas, Abril, 15

Carta de aforamento que faz o comendador de Beselga a Fernão Dias e Inês Mendes, sua mulher, de um casal na Garfanheira, termo de Torres Novas.

Outros Antropónimos: Álvaro de Abrantes, tabelião de Atalaia; Diogo Gonçalves, criado; Diogo Vaz, escudeiro de D. Jorge, filho de D. João II, tabelião em Torres Novas; João Mendes de Assentiz; D. Jorge, filho de D. João II; Jorge Dias, escudeiro da Rainha D. Leonor; Lopo Velho, sobrinho do comendador de Almourol; Mem Martins de Assentiz; Nuno Alves, morador na Vessoana; Rodrigo Eanes, oleiro; Rui Velho, cavaleiro da Casa Real, comendador de Almourol e Beselga.

Outros Topónimos: Almourol; Atalaia; Assentiz; Vessoana.

\section{Juízo dos Órfãos de Ferreira do Alentejo, Livro 1}

[fins séc. XV-iní. XVI]

Instrumento de venda de casas e curral pela quantia de 800 reais.

Outros Antropónimos: Diogo Eanes, clérigo; Estêvão Pais; João Lopes, tabelião; Martim Pires.

51. Cartório Notarial de Torres Vedras, Liv. de Notas, "Cartório", Liv. 48

[15--], Setúbal

Instrumento de emprazamento que fazem Afonso Gonçalves e sua mulher de uma quinta e lagar. 
Outros Antropónimos: Beatriz [...]; Vasco Gil, escrivão.

Outros Topónimos: Rua do Coberto.

52. Cartório Notarial de Torres Vedras, Liv. de Notas, "Cartório", Liv. 37 [2. ${ }^{\circ}$ Documento]

$[15--],[\ldots]$

Instrumento de venda de um chão.

Outros Antropónimos: Gaspar da Serra, filho de Pero [...]; João Borges; Manuel da Rocha; D. Maria.

Outros Topónimos: Barreiro.

53. Cartório Notarial de Torres Vedras, Liv. de Notas, "Cartório", Liv. 68

$[15--],[\ldots]$

Tombo de propriedades de um mosteiro.

Outros Antropónimos: Afonso Esteves; Álvaro de [...]; Álvaro Pires; D. Isabel; João de Ponte; Luís da [...]; Simão Vaz, tabelião.

Outros Topónimos: Barreiro.

54. Núcleo Antigo, 736

[15--], Junho

Carta de sentença envolvendo um homicídio cometido por António Fernandes, degredado para Alcácer Ceguer.

Outros Antropónimos: Gonçalo do Rego; João Dias; Dr. Martim Pinheiro. 


\section{Mosteiro de Arouca, Livro 6}

[15--], Arouca, Fevereiro, 8

Carta de emprazamento que faz o mosteiro de Arouca a Gonçalo Fernandes e Isabel Eanes, sua mulher, de um casal em Lonilhe (?), freguesia de São Tomé de Bitarães, no julgado de Aguiar de Sousa.

Outros Antropónimos: Frei Diogo de Lisboa, monge e confessor; Frei Diogo de Tomar, monge e confessor; Isabel de Almeida, sub-prioresa; D. Milícia de Melo, abadessa.

\section{Cabido da Sé de Lamego, Livro 200}

[15--], [Lamego], Setembro, 16

Emprazamento que faz o Cabido da Sé de Lamego a Manuel Dias e a Filipa Malheiro, sua mulher, de certo casal.

Outros Antropónimos: Afonso Fernandes; Antão Fernandes; Brás Martins; Dr. Diogo Gonçalves, pai de Manuel Dias; licenciado Francisco Coelho; Martim Gonçalves.

Outros Topónimos: Hospital; Valmarinha.

\section{Mosteiro de Santa Cruz de Coimbra, 2. inc., Livro 89}

[15--, Coimbra], Março, 13

Carta de sentença envolvendo um furto realizado por João da Gândara, castelhano, no couto de Torroselo.

Outros Antropónimos: [...] Vaz; Álvaro Fernandes; Estêvão Dias, bacharel, corregedor; Infante D. Fernando; Gomes de Lamego; Jorge Fernandes, tabelião em Coimbra; Dr. Rodrigo Homem.

Outros Topónimos: Coimbra; Seia. 


\section{Mosteiro de Arouca, Livro 8}

1502, Arouca, Março, 2

Carta de emprazamento que faz o mosteiro de Arouca a Fernando Eanes e Catarina Álvares, sua mulher, de um casal em Santo Estêvão (Arouca) por 140 reais brancos de 6 ceitis o real.

Outros Antropónimos: D. Catarina Teixeira, abadessa; Frei Diogo de Lisboa, monge e confessor; Frei Diogo de Tomar, monge e confessor; Estêvão de Figueiredo, notário apostólico; João Eanes; Lopo Gonçalves; D. Maria de Eça, prioresa; Maria Pimentel, sub-prioresa; D. Milícia de Melo, coadjutora.

\section{Ordem de Cristo / Convento de Tomar, 309}

1504, Tomar, Maio, 14

Carta de novo emprazamento que fazem D. João Pereira, comendador de Casevel, e Frei Diogo do Rego, bacharel em direitos, do Desembargo do Rei, visitadores do Mestrado da Ordem de Cristo, a Gil Martins de uma vinha com seu mato, junto de Pias, onde chamam Mata da Ordem.

\section{Juízo dos Órfãos de Pedrógão Grande, Livro 4}

[1508]

Folha de rosto de livro da Confraria do Bem-Aventurado São Roque.

Outros Antropónimos: João [...], meirinho (?); João Rodrigues, besteiro; Lopo Vieira, escrivão.

Outros Topónimos: Pedrógão. 


\section{Juízo dos Órfãos de Aljustrel, Livro 1}

[post. 1508], Agosto, 20

Carta régia de sentença enviada aos juizes de Moura sobre um feito envolvendo Brás Esteves, escudeiro, e sua mulher, Leonor Gonçalves, moradores em Aljustrel, como autores, e Mor Gonçalves, dona viúva, mulher que fora de Vasco Martins Angerinho, morador em Moura, como ré, relacionado com as partilhas de uma herança.

Outros Antropónimos: Aldonça Vasques; André Esteves; Catarina Esteves; Francisco, criado; João Esteves; Margarida Esteves; Vasco Martins.

Outros Topónimos: Viana do Alentejo.

\section{Cabido da Sé de Lamego, Livro 188}

1508, Lamego, Setembro, 20

Carta de emprazamento que faz o cabido da Sé de Lamego, por meio de seu bispo, D. João, membro do Conselho do rei, a João Álvares, filho de João Álvares e Leonor Eanes, morador em Repolhos, de um casal que pertenciam ao bispo e mesa episcopal no dito lugar de Repolhos.

Outros Antropónimos: Afonso Álvares; Catarina Domingues; Diogo Barreiros, criado do bispo; João Lourenço da Seara; Lopo Rodrigues, tabelião público em Lamego; Frei Vicente das Vistas, criado do bispo.

Outros Topónimos: Almacave; Casal do Outeiro; Ferreiros; Longroiva; Rio de Asnos; Souto Covo.

\section{Núcleo Antigo, 752}

[post. 1508, Dezembro, 18]

Carta régia de sentença aos juízes de Évora de Alcobaça da jurisdição do Mosteiro de Alcobaça sobre um feito crime de apelação julgado na Corte e Casa do Cível ordenado pelos ditos juízes e o licenciado Gonçalo 
Dias, corregedor na comarca da Estremadura, cujas partes eram Fernando Álvares, lavrador, morador na dita vila, como autor, contra Afonso Martins, também ali morador, e preso na sua cadeia, por ter ameaçado o autor que o mataria e porque no dia 18 de Dezembro de 1508, às onze horas da noite, estando o autor em casa de Afonso Eanes, juiz, e aparecendo o réu, logo o autor fugira para casa de Catarina Eanes da Serra [ou Seia], onde estivera duas horas antes de se dirigir para sua casa apenas com um pau na mão, e chegando ao canto do relego da dita vila à porta de Rodrigo Afonso onde o réu o esperava já com um desconhecido, atacara os dois, ferindo-os com as suas espadas. Foi o réu condenado pelos juízes locais em 20 cruzados mas o autor não concordou com a sentença e apelou.

Outros Topónimos: Santarém.

\section{Mosteiro de Lorvão, Gaveta 4, Maço 10, Doc. 13}

1509, Évora, Fevereiro, 14

Carta régia de perdão outorgada a João Colaço, morador em Angeja, por ter fugido de João Pinheiro, alcaide de Aveiro, e Brás Afonso, tabelião em Aveiro, que o vinham prender.

Outros Antropónimos: Brás Álvares, escrivão do Desembargo; Gonçalo de Azevedo, do Desembargo do Paço; João Afonso, escrivão do Desembargo; D. Pedro, bispo da Guarda, prior de Santa Cruz de Coimbra, capelão-mor; Pero Álvares, tabelião em Aveiro.

\section{Mosteiro de Arouca, Livro 14}

1509, Arouca, Fevereiro, 18

Carta de emprazamento que faz João Martins, filho de Martim Domingues, a João Gonçalves, alfaiate, de um bacelo perto de Bouças. Contém instrumento de autoridade e consentimento do Mosteiro de Arouca, datado de 24.05.1509. 
Outros Antropónimos: Afonso Rodrigues; Diogo Rodrigues; Gonçalo Eanes, tecelão; Gonçalo Fernandes, tabelião; Jorge Gonçalves, clérigo de missa; D. Milícia de Melo, abadessa; Nuno Eanes de Outeiro; Pero Álvares; Pero de Paiva, clérigo; Simão Peres, carpinteiro.

\section{Juízo dos Órfãos de Castelo de Vide, Livro 4}

1509, Monforte, Junho, 20

Instrumento de partilhas dos bens de Gil Moutoso, feitas por Francisco Moutoso, escudeiro, casado com Leonor Mateus, e António Moutoso, escudeiro, casado com Isabel Dias, seus filhos.

Outros Antropónimos: Afonso Vaz, ermitão do Salvador; Álvaro Afonso; Álvaro Madeira, tabelião das notas; Gil Afonso; D. Jaime, Duque de Bragança; João Moutoso; Maria Aires; Miguel Gil; Pero Afonso; Salvador Martins; Vasco Fernandes.

Outros Topónimos: Alegrete; Alfumara; Arronches; Azambujeira; Borba; Cabeço de Vide; Fonte de Silveira; Marvão; Monforte; Picota; Ribeiro de Ozoa; Vaqueirinho; Veiros; Vila Viçosa.

\section{Ordem de Cristo / Convento de Tomar, 304}

1509, Quintã de Val Covo (Évora), Setembro, 2

Instrumento de emprazamento que faz Frei Diogo do Rego, bacharel em direitos, do desembargo do Rei, visitador da Ordem de Cristo na visitação à comenda de Mendo Marques, na cidade de Évora, a Filipa Moniz, viúva de Mestre António, alemão, cavaleiro da Casa Real e bombardeiro-mor, de uma quintã em Val Covo.

Outros Antropónimos: Domingos Afonso, sapateiro; Estêvão Godinho; Frei Francisco, frei cancelário; Manuel Dias; Rui Boto, clérigo 


\title{
68. Cabido da Sé de Lamego, Livro 204
}

1509, Lamego, Outubro, 25

Instrumento de emprazamento que faz o Cabido da Sé de Lamego ao cónego Nuno Mendes de umas casas na Rua da Pereira, por 110 reais brancos de 6 ceitis.

Outros Antropónimos: Heitor Mendes, cónego, Isabel Rodrigues; Lopo Rodrigues, tabelião; Pero Cardoso, cónego.

\section{Juízo dos Órfãos de Aljustrel, Livro 2}

1511, Lisboa, Novembro, 06

Carta régia de confirmação de sentença de ouvidor relacionada com o roubo, queima e devastação de certas hortas, bem como de roubo de cera e mel a Pero Baião.

Outros Antropónimos: Afonso Fernandes, escrivão; Cristóvão Lourenço, escrivão; Lopo da Fonseca, do Desembargo e ouvidor; Rodrigo Homem, do Desembargo e ouvidor.

\section{Ordem de Santiago / Convento de Palmela, 171}

\author{
1513, Lisboa, Outubro, 5
}

Carta de aforamento que faz D. Jorge, Mestre da Ordem de Santiago, Duque de Coimbra e Senhor de Montemor-o-Novo e Torres Novas, a Álvaro Esteves de uma courela no Lumiar.

Outros Antropónimos: Fernão Dinis; Pedro Eanes, espingardeiro; Pedro Eanes Janeiro.

Outros Topónimos: Portela de Urmeira; Mosteiro de Santos. 


\section{Ordem de São Bento, Mosteiro do Salvador de Braga, Livro 1}

[1513-1521]

Juramento de obediência de D. Inês, abadessa do Mosteiro de Vitorino das Donas, da Ordem de São Bento, diocese de Braga, a Petro Santiquatro, legado (?) apostólico do Papa Leão X.

\section{Mosteiro de Arouca, Livro 74}

1516, Arouca, Dezembro, 2

Carta de emprazamento que faz o mosteiro de Arouca a Leonor Mendes, dona viúva (?), de um casal denominado do Ribeiro em Romariz, freguesia de São Salvador, termo e julgado de Arouca.

Outros Antropónimos: Branca de Almeida; Frei Diogo de Tomar, monge e confessor; Duarte Mendes, irmão de Leonor Mendes; Isabel de Almeida, prioresa; Jorge [... ]; Lopo Rodrigues, tabelião; D. Milícia de Melo, abadessa; Tristão Mendes, sobrinho de Leonor Mendes.

\section{Mosteiro de Arouca, Gaveta 6, Maço 7, N. ${ }^{0} 23$}

$1517,[\ldots]$, Novembro, 4

Instrumento de emprazamento que faz [...] de Freitas e Filipa de Sequeira, sua mulher, a Pero Afonso e sua mulher, de uma quinta.

Outros antropónimos: Lopo Eanes de Basto; Martim Gonçalves da Ramalhosa.

Outros topónimos: Nespereira.

\section{Mosteiro de Arouca, Livro 70}

152[-], Arouca, Janeiro, [ant. 27]

Carta de doação e dote que fazem Gonçalo Gonçalves e sua mulher a [...], com instrumento de autoridade e consentimento da parte do mosteiro de Arouca, da metade de umas casas e de uma leira no burgo. 
Outros Antropónimos: Fernão Dias; João Godins, tabelião; Martim Eanes.

Outros Topónimos: Santa Ovaia.

\section{Juízo dos Órfãos de Ferreira do Alentejo, Livro 11}

1520, Ferreira do Alentejo, [...]

Carta de venda que faz Gonçalo Dias, sapateiro, e Antónia [...], sua mulher, a Estêvão Eanes Gorinho e Beatriz Eanes, de uma vinha.

Outros Antropónimos: Afonso Mourato, tabelião público; João Camaro; Jorge Pires; Maria Esteves Rocinato.

Outros Topónimos: Messejana.

\section{Mosteiro de Arouca, Livro 52}

1520, Vila Nova, Novembro, 14

Carta de emprazamento que faz o mosteiro de Arouca a Fernão Dias e sua mulher, de uns casais em Vila Nova.

Outros Antropónimos: Diogo Pereira, escudeiro (?);Jorge [...], tabelião; Sebastião Gonçalves.

\section{Colegiada de Santo Estêvão de Alfama de Lisboa, Livro 4}

$$
\text { 1522, Lisboa, Junho, } 3
$$

Instrumento de trespasse e consentimento de obrigação feito por Isabel Ximenes, viúva de Nuno Calça, moradora no Bairro dos Escolares, na freguesia de São Vicente, em Lisboa.

Outros Antropónimos: Belchior de Gouveia, capelão da Rainha D. Leonor; Estêvão de Jesus, prior de Santo André do Porto; Luís Fernandes, o Velho, tabelião de Lisboa; Rodrigo Eanes; Vasco de Resende, morador em Lisboa; Violante Gonçalves. 
Outros Topónimos: Igreja de Salvador das Alcáçovas; Santa Marinha, freguesia.

78. Mosteiro de São Bento de Ave Maria do Porto, Maço 6, Doc. olim 248 [1523]

Folha de tombo de prazos da mesa episcopal do Porto. Uma das faces contém a conclusão de um prazo realizado a $21.01 .1523 \mathrm{em}$ que foram testemunhas João Valadares, cavaleiro da Casa Real, Diogo Lourenço, bacharel, e Francisco Pais, bacharel. Na outra face, nos paços do Bispo do Porto D. Pedro da Costa, capelão-mor da Infante D. Isabel, a 22.01.1523, lê-se que como El-Rei mandara abrir no Porto a Rua de Santa Catarina das Flores pelo licenciado António Correia, corregedor na comarca de Entre-Douro e Minho, pela necessidade de que a cidade padecia e para a edificação de um mosteiro novo, e dado que a rua atravessava os chãos e hortas da mesa episcopal, esta emprazava um chão (?) a Pedro Eanes, dourador, morador na Rua da Bainharia, casado com Isabel Fernandes da Rocha, para edificar casas.

\section{Cabido da Sé de Lamego, Livro 185}

1523, Lamego, Junho, 10

Emprazamento que faz o Cabido da Sé de Lamego a Pero Gonçalves, filho de Gonçalo Eanes de Vila Garcia, de certos bens.

Outros Antropónimos: Domingos Gonçalves, prebendeiro do Cabido; João Pires, porteiro do Cabido; Lopo Rodrigues, tabelião; Pero Lourenço.

Outros Topónimos: Casal do Carvalhal; Lameiro de Mouros.

\section{Mosteiro de Arouca, Livro 42}

[post. 1524, Arouca, Fevereiro, 8]

Carta de emprazamento que faz o mosteiro de Arouca a Belchior Mendes de um casal. Contém carta régia de 23.07.1523 autorizando o mosteiro a ter um tabelião cujas escrituras de contratos fossem válidas. 
Outros Antropónimos: João Rodrigues, escudeiro; Romão de Beça.

\title{
81. Mosteiro de Arouca, Livro 12
}

\section{4, Arouca, Março, 2}

Carta de emprazamento que faz o mosteiro de Arouca a Pero Álvares e Madalena Peres, sua mulher, de uma póvoa em Bouções, na freguesia de São Martinho de Pessegueiro (Sever).

Outros Antropónimos: Gonçalo Eanes, escrivão dos prazos; Jorge Gonçalves, abade de Santa [...] e recebedor do Mosteiro de Arouca; Pero Eanes, clérigo e feitor do Mosteiro de Arouca.

\section{Colegiada de Santa Maria da Oliveira de Guimarães, Documentos} Eclesiásticos, Maço 7, n. ${ }^{\circ} \mathbf{2 4}^{37}$

1526, Roma, Outubro, 13

Carta de D. João Baptista, bispo de Caserta e executor apostólico, através da qual ordena ao arcebispo de Braga, D. Diogo de Sousa, que confirmasse o provimento de Pedro Fernandes, clérigo da arquidiocese de Braga, como reitor da igreja de São Pedro de Gominhães (Guimarães), conforme fora determinado por bula do papa Clemente VII (de 31 de Agosto de 1526), cujo teor traslada e dá conhecimento ao referido arcebispo.

\section{Cartório Notarial de Belas- $A, 1 .^{\circ}$ Ofício, Liv. de Notas $n^{\circ} 5$}

\author{
1526, Lisboa, Outubro, 30
}

Carta de venda.

${ }^{37}$ Este sumário foi elaborado por Anísio Saraiva, a quem muito agradecemos a leitura do fragmento em latim. 


\section{Ordem de Santiago / Convento de Palmela, 174}

Canha, 1526, Janeiro, 9

Carta de aforamento que faz D. Jorge, Mestre da Ordem de Santiago, a Bartolomeu de Torres, de um moinho em Canha.

Outros Antropónimos: Diogo Cotão, superior de Palmela e prior de Santa Maria de Alcácer do Sal; Francisco Coelho, escrivão; Pero Velho.

\section{Mosteiro de Arouca, Livro 10}

[1531?], Arouca

Carta de emprazamento que faz o mosteiro de Arouca a [?] de uma propriedade em Penedo (Furadouro, Torres Vedras).

Outros Antropónimos: António Fernandes; António Lopes, estudante de Artes; Diogo Dias; Francisco [... ]; Gonçalo Eanes, tabelião; João Fernandes; Simão Fernandes, estudante de Artes.

Outros Topónimos: Alcobaça; Bemposta; Carrasqueira; Lisboa; Pedrulhos; Poço do Chão (Lisboa).

\section{Mesa da Consciência e Ordens - Tombos de Comendas, 382}

1531, Beja, Setembro, 27

Carta de venda que faz Luzia Fernandes, mulher de Afonso Vaz, a Francisco Martins Colaço, casado com Leonor Mendes, de uma vinha no termo da cidade de Beja, por 3.000 reais brancos.

Outros Antropónimos: João Luís, pisoeiro; João Álvares e Estêvão da Maia, escudeiros do rei; Fernão de Cisneiros, escudeiro, todos moradores em Beja; João de Pedroso, tabelião em Beja.

Outros Topónimos: Breceais. 


\section{Mosteiro de Arouca, Livro 18}

1532, Arouca, Agosto, $[\ldots]$

Carta de emprazamento que faz o mosteiro de Arouca a João Rodrigues e Maria Dias, sua mulher, de um casal em Fremil, onde vivia Francisco Eanes e Beatriz Eanes, sua mulher, que ora renunciavam ao dito casal.

Outros Antropónimos: António [...]; Diogo Pires; Gonçalo Eanes, escrivão dos prazos; D. Isabel Pereira, prioresa; Maria de Almeida, subprioresa; D. Milícia de Melo, abadessa.

88. Cartório Notarial de Belas- $A, 1 .^{\circ}$ Ofício, Liv. de Notas n. $^{\circ} 4$

$1533,[\ldots]$, Fevereiro, 17

Letra apostólica trasladada em português.

\section{Mosteiro de Arouca, Livro 40}

[post. 1534, Arouca, Fevereiro, 8]

Carta de emprazamento que faz o mosteiro de Arouca a Gonçalo Teixeira, tabelião e morador em Arouca, e Filipa Vieira, sua mulher, de uma terra e mato denominada de Lameiro da Ribeira nas Redondas, que for a comprada a António Pires e Domingos Eanes Damilo e suas mulheres, na freguesia de Santa Ovaia, no termo de Arouca.

Outros Antropónimos: António Pires; Baltasar Dias; Domingos Eanes Damilo (?); Filipa Brandoa, subprioresa; Gonçalo de Beça, escrivão do mosteiro; D. Isabel de Castro, prioresa; João Pires de Menhãos; João Rodrigues Carvalho; Jorge Eanes de Menhãos; D. Leonor de Albuquerque, abadessa; Pero Eanes Malfrade, criado da abadessa Pero Pires da Touta.

Outros Topónimos: Casal de Minhãos. 


\section{Mosteiro de Arouca, Livro 59}

[post. 1534?], Arouca

Carta de emprazamento que faz o mosteiro de Arouca a Duarte Gonçalves e Maria Gonçalves de um casal em Cambra (Lafões).

Outros Antropónimos: António Machado; Gonçalo de Beça, bacharel; D. Isabel de Castro, prioresa; João Viegas, escrivão do mosteiro; D. Leonor de Albuquerque, abadessa; D. Maria de Berredo, subprioresa; Pero Eanes Malfrade.

Outros Topónimos: Casal do Hospital de Viseu; Casal de Santa Cruz; Casal de São Cristóvão.

\section{Mosteiro de Arouca, Livro 73}

1535, Arouca, Janeiro, 20

Carta de emprazamento que faz o mosteiro de Arouca a António Fernandes e Margarida Peres, sua mulher, de uma leira junto do burgo atrás das casas de André Pires.

Outros Antropónimos: Diogo Dias; Gonçalo Eanes, escrivão; Gonçalo Gonçalves de Vila Nova; Isabel Dias; Isabel Pereira, prioresa; João Dias de Rondevoso; João Fernandes; João P[...]; João Pires, ferreiro; Maria de Almeida, subprioresa; D. Milícia de Melo, abadessa.

\section{Cartório Notarial de Torres Vedras, Liv. de Notas, "Cartório",} Liv. 26

[1539?], Torres Vedras, Outubro, 26

Instrumento de venda das casas onde vive Belchior Lamego, escrivão perante o corregedor, na Rua do Santo Espírito.

Outros Antropónimos: António Lopes, beneficiado na Igreja de São Pedro e São Miguel de Torres Vedras; Tomé da Rocha, tabelião; Violante [...]. 
Outros Topónimos: Alcabrichel; Casal Queimado; Igreja de São Miguel de Torres Vedras; Igreja de São Pedro de Torres Vedras.

\section{Mosteiro de Arouca, Livro 144}

$1540,[\ldots]$

Bula em latim.

Outros Antropónimos: Gonçalo de Beça; João Baptista Sangalho.

Outros Topónimos: Santa Marinha de Tropeço, termo de Arouca, diocese de Lamego.

94. Cartório Notarial de Torres Vedras, Liv. de Notas, "Cartório", Liv. 34

1541, Lisboa, Agosto, 19

Carta régia de concessão dos privilégios de regedor, governador e desembargador da Casa da Suplicação e do Cível, a João Álvares, sapateiro, morador em Torres Vedras, amo do Dr. Gaspar de Carvalho, do Conselho do Rei e do Desembargo do Paço.

Outros Antropónimos: Agostinho [...]; Álvaro Fernandes, doutor, do Conselho e chanceler-mor; Manuel Gomes da Rosa; Pero Gomes.

95. Cartório Notarial de Torres Vedras, Liv. de Notas, "Cartório", Liv. 73

1544, Torres Vedras, Fevereiro, 22

Instrumento de obrigação de missas instituída por Catarina Colaça, viúva.

Outros Antropónimos: Afonso Ribeiro, marido de Joana Leitoa; António Lopes, beneficiado nas igrejas de São Pedro e São Miguel de Torres Vedras; Hilária, filha de Joana Leitoa; Joana Leitoa, filha de Catarina Colaça;

Outros Topónimos: Casal de Santa Maria; Repelão; São Folgado. 


\section{Mesa da Consciência e Ordens - Tombos de Comendas, Livro 277}

\section{4, Braga, Fevereiro, 26}

Carta de renovação de emprazamento que faz o Cabido da Sé de Braga a João Afonso, clérigo de missa, criado de António Velho, abade de Moure

e Águas Santas, morador em Braga, que comprara o direito e vidas de um prazo de umas casas da obra da Sé na Rua Verde a Fernão Quinteiro, pagando 150 reais em dinheiro por ano.

Outros Antropónimos: Aires da Costa, cónego prebendado na Sé de Braga; António de Aguiar; António Lopes, criado de D. Jorge; António Rodrigues, cónego prebendado na Sé de Braga; Belchior da Silva, cónego prebendado na Sé de Braga; Diogo de Andrade, cónego prebendado na Sé de Braga; Diogo Fernandes, cónego prebendado na Sé de Braga; Filipe [...], escrivão do cabido; Filipe Campelo, cónego prebendado na Sé de Braga; Francisco de Castro, cónego prebendado na Sé de Braga; Francisco Gonçalves, cónego prebendado na Sé de Braga; Francisco de Sampaio, clérigo do coro; Geraldo de Castilho, cónego prebendado na Sé de Braga; Jacome de Castilho, cónego prebendado na Sé de Braga; Jacome Vieira, cónego prebendado na Sé de Braga; Jerónimo Mateus, cónego prebendado na Sé de Braga; João Afonso de Aveleda; João Martins, cónego prebendado na Sé de Braga; Jorge Madeira, cónego prebendado na Sé de Braga; Lopo Dias, cónego prebendado na Sé de Braga; D. Martinho, arcebispo; Pero Fernandes, cónego prebendado na Sé de Braga; Sebastião Gonçalves, Licenciado e provisor e vigário-geral no arcebispado de Braga; Tristão Luís, cónego prebendado na Sé de Braga.

Outros Topónimos: Capela de Santa Marta; Hospital de São Marcos; couto de Vimieiro.

\section{Mosteiro de Arouca, Livro 78 [1. ${ }^{\circ}$ documento]}

1546, Arouca, Novembro, 16

Bula em latim emitida pelo Papa Paulo III em favor de Diogo Dias, clérigo cura de São Pedro de Arouca. 
Outros Antropónimos: Gonçalo de Beça.

Outros Topónimos: Lamego; Lisboa; Santarém.

\section{Mosteiro de Arouca, Livro 79}

1549, Arouca, Setembro, 22

Carta de emprazamento que faz o mosteiro de Arouca a Luís Eanes e Catarina Dias, sua mulher, de um casal em Romariz, que antes trazia João Eanes, seu pai.

Outros Antropónimos: Ana de Escobar; Domingos Dias, almocreve; Domingos Eanes de Camelo; Duarte de Almeida; Gonçalo Eanes, escrivão dos prazos; D. Isabel de Castro, subprioresa; Maria de Almeida, prioresa; D. Milícia de Melo, abadessa.

\section{Mosteiro de Arouca, Livro 57}

1554, Arouca, Abril, 19

Carta de emprazamento que faz o mosteiro de Arouca a João Fernandes e sua mulher de um casal.

Outros Antropónimos: Gonçalo Eanes, tabelião; Frei Luís de Almança, confessor; Frei Pedro Adegeiro (?); Pero Eanes Malfrade.

\section{Ordem de Avis / Convento de São Bento, Livro 1}

[post. 1556], Lisboa, Abril

Instrumento relacionado com a venda de umas casas, hortas e olivais nos paços de Xabregas a António Álvares, almoxarife dos ditos paços.

Outros Antropónimos: António Gonçalves; Baltasar Leal, criado de Bernardim Esteves; Bernardim Esteves, licenciado e procurador da coroa; Diogo Lobo; Isabel Gomes; Henrique Nunes, tabelião; Manuel Nunes, 
moço da câmara da infante D. Maria; Manuel Vaz, moço da câmara do rei; infante D. Maria.

Outros Topónimos: Convento de São Francisco de Lisboa; Mosteiro da Madre de Deus; Rio Tejo; Xabregas;

\section{Mosteiro de Arouca, Livro 15}

1558, Lisboa, Agosto, 12

Carta régia nomeando João Viegas, morador em Arouca, como juiz dos órfãos, inquiridor e distribuidor em Arouca como o fora Romão de Beça, que se finara, por ter casado com a filha deste.

Outros Antropónimos: Antónia Barbosa; Antónia de Beça; António Vieira, escrivão; D. Constantino de Bragança; D. Gonçalo Pinheiro, bispo de Viseu; Gonçalo Teixeira, tabelião; João de [...], escrivão; João Aranha, tabelião em Arouca; Roque Vieira; D. Simão da Cunha.

\section{Mosteiro de Arouca, Livro 81}

1561, Arouca, Janeiro, 30

Carta de emprazamento que faz o mosteiro de Arouca a Pero Eanes Duro de um casal em Vadonalde, freguesia de São Miguel de Arouca.

Outros Antropónimos: Domingos Fernandes; Gonçalo de Beça, feitor; D. Isabel de Castro, prioresa; João Viegas, escrivão dos prazos; D. Leonor de Albuquerque, abadessa; D. Maria de Berredo, subprioresa; Pero Eanes Malfrade.

\section{Mosteiro de Arouca, Livro 79}

1566, Arouca, Abril, 2

Carta de emprazamento que faz o mosteiro de Arouca a Adão Pires e Maria Gonçalves, sua mulher, moradores no burgo, de umas casas terreiras no cimo do burgo de Vila Meã junto das casas do concelho. 
Outros Antropónimos: Frei Ambrósio; António Dias; Filipa Brandoa, subprioresa; Gonçalo de Beça, escrivão do mosteiro; Gonçalo Pires de Azevedo; D. Isabel de Castro, prioresa; D. Leonor de Albuquerque, abadessa; Pero Eanes Malfrade.

\section{Mosteiro de Arouca, Livro 32}

Roma, 1567

Bula em latim de pensão de 50 cruzados em favor de Gonçalo de Beja.

Outros Topónimos: Igreja de São Miguel.

\section{Mosteiro de Arouca, Livro 64}

[post. 1595, Porto, Novembro, 10]

Carta de Diogo Brandão, fidalgo da Casa Real, vedor da Fazenda no Porto, confirmando o privilégio dos alcafates do número do Porto a Manuel Manso.

Outros Antropónimos: Baltasar do Couto, escrivão dos contos do Porto; Brás Dias; Gaspar [...]; Luís Figueira.

Outros Topónimos: Belmonte.

\section{Mosteiro de Arouca, Livro 78 [2..$^{\circ}$ documento]}

1598, Lisboa, Janeiro, 23

Carta régia concedendo a Constantino de Castro, tabelião do público e judicial do concelho de Gaia, termo do Porto, licença para ter uma pessoa que o ajudasse.

Outros Antropónimos: Belchior do Amaral, do Conselho do Rei e desembargador do Paço; Damião de Aguiar, do Conselho do Rei e desembargador do Paço; Dr. Jerónimo Pereira de Sá, do Conselho do Rei e desembargador do Paço; Miguel Couceiro. 


\section{Manuscritos da Livraria, 1221}

[finais do séc. XVI-inícios do séc. XVII]

Folhas de dois processos judiciais diferentes nas guardas da encadernação. O único que é possivel ler envolve uma contenda acerca de um casal.

Outros Antropónimos: António Fernandes; António Lopes.

\section{Cabido da Sé de Lamego, Livro 72}

Lisboa, [1678-1683], [...]

Dispensa matrimonial em latim.

Outros Antropónimos: Domingos Fernandes Gomes, filho de Isabel Fernandes; Domingos Lopes Lara; Isabel Fernandes; Marcelus Duratius, Arcebispo de Calcedónia; Petrus Paulus Castreia;

Outros Topónimos: Lamego. 


\section{Apêndice}

\section{Lista de fragmentos da Torre do Tombo em pergaminho contendo obras literárias e históricas em português}

A descrição codicológica bem como informações pertinentes adicionais dos fragmentos listados infra pode ser obtida na base de dados BITAGAP na Internet pesquisando por autor, obra, cota ou manid (n. ${ }^{\circ}$ de identificação de manuscrito).

\section{Obras identificadas}

Afonso X, História Geral

Fragmentos, Caixa 21, n. ${ }^{\circ} 29^{38}$ (manid 1495)

Fragmentos, Caixa 21, n. ${ }^{\circ} 30^{39}$ (manid 1502)

Fragmentos, Caixa 21, n. ${ }^{\circ} 31^{40}$ (manid 1501)

Fragmentos, Caixa 21, n. ${ }^{\mathrm{o}} 32^{41}$ (manid 1500)

\section{Afonso X, Primeira Partida}

Colegiada de Santa Iria de Santarém, Livro 1 (manid 1448) (2 $^{42}$

Mosteiro de Santa Cruz de Coimbra, Pasta 41, doc. s/n..$^{043}$ (manid 3287)

\section{Afonso X, Segunda Partida}

Gavetas, VII, Maço 15, n. ${ }^{\mathrm{o}} 2^{44}$ (manid 1147)

${ }^{38}$ Publicado em LEITE, Mariana - A General Estoria de Afonso X em Portugal: as múltiplas formas de receção do texto alfonsino entre os séculos XIV e XVI. Porto: Faculdade de Letras da Universidade do Porto, 2012, p. 285-287.

${ }^{39}$ Publicado em IDEM - A General Estoria ..., cit., p. 289-291.

${ }^{40}$ Publicado em IDEM - A General Estoria ..., cit., p. 293-296.

${ }^{41}$ Publicado em IDEM - A General Estoria ..., cit., p. 297-300.

${ }^{42}$ Publicado em FERREIRA, José de Azevedo-Alphonse X: Primeyra Partida: Édition et Étude. Braga: Instituto Nacional de Investigação Científica, 1980, p. lvi-lxi.

${ }^{43}$ Publicado em ASKINS et alii, 2002, 47-49.

${ }^{44}$ Publicado em FERREIRA, 1987, 289-291. 


\section{Afonso X, Terceira Partida}

Espólio Silva Marques, Caixa 1, n. ${ }^{\circ} 4^{45}$ (manid 1440)

Mosteiro de Santa Cruz de Coimbra, 2. ${ }^{a}$ inc., Maço 236, doc. s/n. ${ }^{046}$ (manid 4213)

\section{Afonso X, Quinta Partida}

Fragmentos, Caixa 21, n. ${ }^{\circ} 3^{47}$ (manid 3390)

Bernardo de Brihuega, Vida e Paixão dos Quarenta Cavalheiros

Fragmentos, Caixa 20, n. ${ }^{\circ} 10^{48}$ (manid 1750)

D. Dinis, Cantigas

Fragmentos, Caixa 20, n. ${ }^{\circ} 2^{49}$ (manid 1817)

João Cassiano, Colações dos Santos Padres do Egipto

Fragmentos, Caixa 21, n. ${ }^{\circ}{ }^{50}$ (manid 3405)

Fragmentos, Caixa 21, n. ${ }^{\circ} 18^{51}$ (manid 1859)

Fragmentos, Caixa 21, n. ${ }^{\circ} 19^{52}$ (manid 1164)

João Cassiano, Estabelecimentos dos Mosteiros

Cartório Notarial de Torres Vedras, “Cartório”, Livro $70^{53}$ (manid 4319)

Tancredus Bononiensis, Ordo Iudiciarius

Colecção Especial, Maço 10, Doc. $38^{54}$ (manid 3528)

\footnotetext{
${ }^{45}$ Publicado em FERREIRA, 1980, 124-132.

${ }^{46}$ Publicado em FERREIRA, 1987, 289-291.

${ }^{47}$ Publicado em ASKINS, Arthur L.-F. et alii - Fragmentos de textos..., cit., p. 51-55.

${ }^{48}$ Publicado em CEPEDA, Isabel Vilares - Os "Quarenta..., cit., p. 507-514.

${ }^{49}$ Publicado em SHARRER, Harvey L. - Fragmentos de sete..., cit., p. 13-29; FERREIRA, Manuel Pedro - Cantus coronatus..., cit.

${ }^{50}$ Publicado em ASKINS, Arthur L.-F. et alii - Fragmentos de textos..., cit., p. 44-46.

${ }^{51}$ Publicado em IDEM - Fragmentos de textos ..., cit., p. 39-41.

${ }^{52}$ Publicado em AZEVEDO, Pedro de - Fragmento de um..., cit., p. 36-39.

${ }^{53}$ Publicado em RICO, Maria João Toscano - A projecção..., cit., p. 123-148.

${ }^{54}$ Publicado em ASKINS, Arthur L.-F. et alii - Fragmentos de textos ..., cit., p. 59-62.
} 
Convento da Santíssima Trindade de Santarém, 1. inc., Maço 10, n. ${ }^{\circ} 28^{55}$ (manid 4311)

Teodorico Borgognoni, Livro de Cirurgia

Fragmentos, Caixa 20, n. ${ }^{\circ} 9^{56}$ (manid 1045)

Tito Lívio, Décadas

Cartório Notarial da Lourinhã, Caixa 2, Livro 7 (manid 4338)

Orto do Esposo

Fragmentos, Caixa 21, n. ${ }^{\mathrm{o}} 23^{57}$ (manid 3397)

Fragmentos, Caixa 21, n. ${ }^{\circ} 26^{58}$ (manid 3527$)$

Mosteiro de Lorvão, Livro $10^{59}$ (manid 3530)

Vida de São Nicolau de Mira

Fragmentos, Caixa 21, n. ${ }^{\circ} 1^{60}$ (manid 1148)

Foral de Tonhe

Fragmentos, Caixa 21, n. ${ }^{\circ} 20$ (manid 3518)

\section{Obras por identificar}

Comentários Religiosos:

Convento de Santo Elói de Lisboa, Livro 18 [reforço da capa] (manid 6116) Convento de Santo Elói de Lisboa, Livro 18 [reforço da capa] (manid 6117) Fragmentos, Caixa 21, n. ${ }^{\circ} 22$ [reforço da capa ${ }^{61}$ (manid 3401)

\footnotetext{
${ }^{55}$ Ultimamos a publicação deste fragmento.

${ }^{56}$ Publicado em ASKINS, Arthur L.-F. et alii - Fragmentos de textos..., cit., p. 63-65.

${ }^{57}$ Publicado em IDEM - Fragmentos de textos ..., cit., p. 30-34.

${ }^{58}$ Publicado em IDEM - Fragmentos de textos ..., cit., p. 37-38.

${ }^{59}$ Publicado em IDEM - Fragmentos de textos..., cit., p. 36.

${ }^{60}$ Publicado em AZEVEDO, Pedro de - Dois fragmentos..., cit., p. 581-586.

${ }^{61}$ Publicado em ASKINS, Arthur L.-F. et alii - Fragmentos de textos ..., cit., p. 28-29.
} 
Fragmentos, Caixa 21, n. ${ }^{\circ} 23$ [reforço da capa] ${ }^{62}$ (manid 3532)

Fragmentos, Caixa 21, n. ${ }^{\circ} 24$ [reforço da capa] ${ }^{63}$ (manid 3410)

Mosteiro de Alcobaça, Livro 64 [reforço da capa] (manid 4447)

Mosteiro de Alcobaça, Livro 65 [reforço da capa] (manid 4448)

Mosteiro de Alcobaça, Livro 115 [reforço da capa] (manid 4435)

Mosteiro de Lorvão, Livro $12^{64}$ (manid 3526)

Comentários de Direito:

Fragmentos, Caixa 21, n. ${ }^{\text {o }} 21^{65}$ (manid 3406)

Comentários de Medicina e Farmacopeia:

Manuscritos da Livraria, $180^{66}$ (manid 3398)

${ }^{62}$ Publicado em ASKINS et alii, 2002, 22-23; NUNES, Irene Freire - Pequenas tiras. In Da decifração em textos medievais: IV Colóquio da Seç̧ão Portuguesa da Associação Hispânica de Literatura Medieval. Lisboa: Colibri, 2003, p. 217-222.

${ }_{63}$ Publicado em ASKINS, Arthur L.-F. et alii - Fragmentos de textos..., cit., p. 26-28.

${ }^{64}$ Publicado em IDEM - Fragmentos de textos..., cit., p. 24-25.

${ }^{65}$ Publicado em IDEM - Fragmentos de textos..., cit., p. 58.

${ }^{66}$ Publicado em IDEM - Fragmentos de textos..., cit., p. 68. 